\title{
Racial differences in androgen metabolism and receptor signaling
}

\section{in prostate cancer}

Swathi Ramakrishnan ${ }^{1 *}$, Eduardo Cortes-Gomez ${ }^{2}$, Kristopher Attwood², Rick A Kittles ${ }^{3}$, Jianmin Wang², Spencer R Rosario², Dominic J Smiraglia4, Gissou Azabdaftari ${ }^{5}$, James L Mohler $^{6}$, Wendy J Huss ${ }^{1}$, and Anna Woloszynska ${ }^{1^{*}}$

\section{Affiliations}

1Department of Pharmacology and Therapeutics, Roswell Park Comprehensive Cancer Center, Buffalo, NY 14263, USA

${ }^{2}$ Department of Bioinformatics and BioStatistics, Roswell Park Comprehensive Cancer Center, Buffalo, NY 14263, USA

${ }^{3}$ Department of Population Sciences, City of Hope Comprehensive Cancer Center, Duarte, CA 91010, USA

${ }^{4}$ Department of Cancer Genetics and Genomics, Roswell Park Comprehensive Cancer Center, Buffalo, NY 14263, USA

${ }^{5}$ Department of Pathology, Roswell Park Comprehensive Cancer Center, Buffalo, NY 14263, USA

${ }^{6}$ Department of Urology, Roswell Park Comprehensive Cancer Center, Buffalo, NY 14263, USA

*Corresponding authors: anna.woloszynska-read@roswellpark.org, Telephone: 716845-8495 and swathi.ramakrishnan@roswellpark.org Telephone: 716-845-8025, Fax: $716-845-1258$

Conflict of interest None 


\section{Abstract}

Dihydrotestosterone (DHT) and testosterone ( $\mathrm{T}$ ) mediated androgen receptor (AR) nuclear translocation initiates transcription of AR target genes that are pivotal for prostate cancer (PrCa) development and progression. Here we provide data indicating that in contrast to European American (EA) men, African American (AA) men with localized PrCa can exploit an alternative progesterone-androsterone-5a-androstanedione pathway for DHT biosynthesis. Enzymes that are involved in alternate pathways of DHT biosynthesis are elevated in PrCa tissues from AA men, compared to EA men, and also correlated with increased serum DHT levels. In addition, higher serum DHT levels reflect increased RNA expression of AR target genes in PrCa tissues from AA men. Interestingly, serum $T$ but not DHT levels are significantly lower in AA men compared to EA men with PrCa. Furthermore, serum progesterone and related intermediate metabolites levels that are produced during alternate pathways of DHT biosynthesis are significantly lower in AA men with $\mathrm{PrCa}$ and associated with a shorter time to disease progression. These data highlight that androgen biosynthesis is altered in therapy naïve localized PrCa in AA men, and can potentially serve as prognostic indicators of disease progression.

\section{Significance}

Our work provides a rationale to examine potential pharmacological interventions that target androgen biosynthesis and AR signaling earlier in the disease continuum in AA men with PrCa. Additionally, our study lays the groundwork for developing serum measurements of intermediate androgen metabolites as PrCa prognostic biomarkers. 


\section{Introduction}

Hormone-driven androgen receptor (AR) and its transcriptional activity is a focal signaling axis in prostate cancer $(\mathrm{PrCa})^{1-3}$. Androgens, including dihydrotestosterone $(\mathrm{DHT})$ and testosterone $(\mathrm{T})$, are synthesized through the conversion of different intermediate metabolites that are regulated by several enzymes ${ }^{4}$. DHT and $\mathrm{T}$ bind to and initiate AR nuclear translocation resulting in the transcription of several AR target genes that control the cell cycle, apoptosis, differentiation, and other processes necessary for PrCa development and progression $2,5-11$. Therefore, both androgen synthesis and AR activity are the primary targets of systemic therapies used in $\mathrm{PrCa}^{1-3}$. PrCa from African American (AA) men have increased AR transcriptional activity compared to European American (EA) men. Importantly, the association between DHT or T levels in the serum and AR expression/activity in PrCa tissue from AA men has not been established ${ }^{12,13}$. In EA men, there is some evidence of a negative correlation between $\mathrm{T}$ levels in the serum and $A R$ protein expression but not transcriptional activity in PrCa tissues ${ }^{14}$.

$\mathrm{DHT}$ and $\mathrm{T}$ are primarily produced in the Leydig cells of the testis, with small quantities being synthesized in the adrenal glands ${ }^{15,}{ }^{16}$. In the non-diseased state, AA men have increased DHT levels in the serum compared to EA men ${ }^{3,17-20}$. Prostate tumors themselves are also known to produce their own androgens, especially in the setting of androgen deprivation therapies ${ }^{21-26}$. Irrespective of the location, DHT and T de novo synthesis requires cholesterol as the primary precursor ${ }^{4}$. In AA men, high levels of total cholesterol in the serum are associated with high-risk PrCa disease and are considered a significant risk factor for PrCa recurrence ${ }^{27,28}$. Whether serum cholesterol levels are indicative of increased DHT and T biosynthesis is unknown. Cholesterol is converted to 
pregnenolone that can lead to $\mathrm{T}$ synthesis through three possible pathways: (1) dehydroepiandrosterone (DHEA)-androstenedione (ASD), (2) DHEA-androstenediol, or (3) progesterone-ASD conversion ${ }^{1,29,30}$. Similarly, DHT can be synthesized through three pathways that involve: (1) DHEA-T, (2) progesterone-androsterone (AND)androstanedione (5a-dione), or (3) DHEA-ASD-5a-dione ${ }^{1,29,30}$. Compared to EA men, PrCa tissues from AA men have significantly higher levels of intermediate androgen metabolites, such as DHEA and ASD but not DHT or $\mathrm{T}^{31,32}$. Whether there are racespecific differences in DHT, T, and intermediate metabolite levels in the adjacent nontumor tissues is unknown. The enzymes regulating DHT and T synthesis include

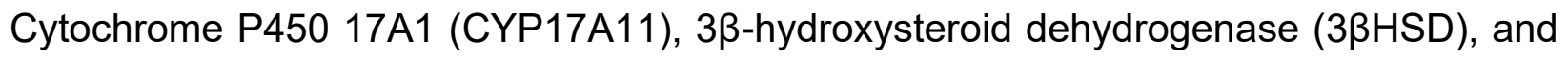
Aldo-keto reductase family $1(\mathrm{AKR} 1 \mathrm{C})^{4}$. Thus far, only a single study has reported racespecific differences in the RNA expression of enzymes involved in androgen metabolism ${ }^{33}$. These enzymes are also known to harbor single nucleotide polymorphisms (SNPs) found at different frequencies in AA and EA men in healthy and diseased states ${ }^{24}$ 34-38. Although the functional consequences of these SNPs remain poorly understood, they are associated with clinicopathological parameters and occur at different frequencies in diverse populations ${ }^{24,34-43}$.

There are limited comparative studies of androgens and intermediate metabolites in the serum of AA and EA men at initial PrCa diagnosis and before radical prostatectomy $(\mathrm{RP})^{18,44-46}$. Here, we investigate differences in levels of androgen metabolites in the serum in relation to clinical outcomes and $A R$ expression/activity of $A A$ and $E A$ men at the time of PrCa diagnosis. Our results show that the expression of enzymes that synthesize DHT through alternative pathways is increased in $\mathrm{PrCa}$ from AA men 
compared to EA men. We show for the first time that the expression of enzymes involved in the alternative DHT synthesis pathways correlates with DHT levels in the serum of AA but not EA men with PrCa. We also find that DHT levels in the serum correlate to AR transcriptional activity in PrCa tissues from AA but not EA men. Interestingly, in the serum, low levels of $T$ and a subset of intermediate metabolites more commonly found in AA men with $\mathrm{PrCa}$ associate with shorter time to disease progression. Finally, we identified a novel SNP in the CYP11B family of enzymes that lead to aldosterone synthesis at an increased frequency in AA men with PrCa. In summary, our data indicate that AA men more frequently utilize alternative pathways of DHT synthesis, and that the levels of androgen intermediate metabolites in the serum at the time of RP can be indicators of clinical outcomes in $A A$ and $E A$ men. 


\section{Results}

\section{Androgen synthesis enzymes from the alternate pathway are upregulated in PrCa} from AA men

To investigate racial disparities at the time of RP, we utilized an unbiased RNA sequencing approach to determine differences in the cellular transcriptome in $\mathrm{PrCa}$ and adjacent non-tumor tissues from $A A$ men and EA men. We measured differences in clinical samples hereafter referred to as Roswell Park Cohort 1 (Supplementary Table 1). RNA sequencing analyses revealed that close to $50 \%$ of the top 500 upregulated and 500 downregulated genes are protein coding genes when comparing PrCa from AA and EA men in Roswell Park Cohort 1 (Figure 1A, Demographics in Supplementary Table 2). Interestingly, the remainder of the dysregulated genes belong to families of poorly understood long non-coding RNAs, processed pseudogenes, and antisense RNAs (Figure 1A). We investigated pathways that are enriched in $\mathrm{PrCa}$ derived from AA men compared to EA men using Genego MetaCore. These analyses revealed that androgen metabolism is one of the top 5 pathways upregulated in PrCa derived from AA men compared to EA men Roswell Park Cohort 1 (Figure 1B, Supplementary Table 3). Specifically, the AKR1C1 that produces DHT using alternative pathways were upregulated in PrCa and adjacent non-tumor tissue AA men compared to EA men (Figure 2A, Supplementary Table 3). We validated the expression of a subset of these enzymes in matched clinical samples from AA $(n=5)$ and EA men $(n=4)$ (Figure 2B-C, Supplementary Figure 1, primers listed in Supplementary Table 4).

We applied a metabolism-specific analysis pipeline to Roswell Park Cohort $1^{47}$. We found that AKR1C, UGT1, and SRD5A gene families were significantly different 
between PrCa from AA and EA men (Supplementary Table 5-6). These genes were included in the gene ontologies of drug metabolism by other enzymes and steroid hormone biosynthesis. We extended the metabolism-specific pipeline to The Cancer Genome Atlas dataset (TCGA) (AA $n=43$, EA $n=270$ ) (Supplementary Table 5-6). This discovery pipeline revealed race-specific differences in metabolic pathways, such as tryptophan metabolism, norepinephrine, and purine biosynthesis in the Roswell Park Cohort 1 and TCGA PrCa database (Supplementary Table 5-6). Our results suggested that androgen metabolism and other metabolic pathways are already dysregulated at the time of RP in PrCa and adjacent non-tumor tissues in AA compared to EA men.

\section{Serum DHT levels and expression of androgen metabolizing enzymes differ between AA and EA men with PrCa}

The upregulation of RNAs encoding enzymes involved in alternate pathways of androgen synthesis in AA men led us to hypothesize that these may reflect differences in levels of the AR binding androgens, DHT and T. We measured DHT and T in serum since they are synthesized in the different sites, including the Leydig cells of the testis, adrenal glands and tumor/adjacent non-tumor tissues, and freely circulate in the serum ${ }^{48}$. Furthermore, these measurements provide us with a systemic view of androgen levels in AA and EA men with PrCa. We used high-pressure liquid chromatographic assays with tandem mass spectral detection (LC-MS/MS) ${ }^{49}$ to measure levels of $\mathrm{T}$ and $\mathrm{DHT}$ in the serum of AA ( $n=38)$ and EA ( $n=69)$ men with PrCa treated at Roswell Park referred to as Roswell Park Cohort 2 (Supplementary Table 1, Demographics in Supplementary Table 7). The calibrations and performance data are listed in Supplementary data 8 and 9. With the exception of one clinical sample, all the serum samples were obtained from 
patients that received no prior treatments. The median levels of $\mathrm{T}$ in the serum were significantly different $(p<0.05)$ with lower levels of $T$ more commonly found in $A A$ compared to EA men with PrCa in Roswell Park Cohort 2 (Figure 3, Table 1). The median levels of DHT in the serum Roswell Park Cohort 2 was similar between the two racial groups (Figure 3, Table 1). In the pooled analyses of Roswell Park Cohort 2 that includes both AA and EA men, the median levels of $T(p<0.01)$ and DHT $(p=0.053)$ in the serum were lower in men with PrCa >= Gleason score 7 compared to men with PrCa Gleason score <7 (Supplementary Table 10).

Next, we determined if DHT levels in the serum are indicative of tissue transcript levels of upregulated enzyme encoding genes involved in alternate pathways of DHT biosynthesis. We developed scores using the Gene Set Variation Analysis (GSVA) for gene expression of multiple enzymes involved in alternate pathways, namely $A K R 1 C 3$, DHRS9, HSD17B3, HSD3B1, HSD3B2, RDH5, SRD5A1, SRD5A2 and CYP19A1, for both PrCa and adjacent non-tumor tissues from AA and EA men. We performed these analyses on overlapping samples between Roswell Park Cohorts 1 and 2 (Supplementary Table 1). Significantly, we found that DHT levels in the serum were negatively correlated with GSVA score in adjacent non-tumor tissues $(r=-0.86, p<0.05)$ only in AA men (Figure 4) but not in EA men with PrCa (Figure 4). However, when gene expression in PrCa tissues is normalized to gene expression in adjacent non-tumor tissue, we found a trend towards a positive correlation between genes involved in the alternate pathway for DHT synthesis and DHT levels in the serum ( $r=0.62)$ (Figure 4). Furthermore, using the Fisher's $r$ to $z$ conversion we found that there is a significant difference between AA and EA men in correlation patterns between DHT levels in the 
serum and expression of enzymes involved in the alternate pathway for DHT synthesis in PrCa and adjacent non-tumor tissues ( $p<0.05$, Figure 4, boxed p-values). Overall, our results indicate that DHT levels in the serum can potentially be used as surrogate markers for the expression of enzymes involved in alternate pathways for DHT biosynthesis in PrCa and adjacent non-tumor tissue from AA men.

\section{Alternate DHT biosynthesis pathways are used by AA men at PrCa diagnosis}

Since the median levels of $\mathrm{T}$ but not DHT in the serum of AA men with PrCa was significantly lower compared to EA men with PrCa (Figure 3, Table 1), we investigated if this was potentially due to differences in pathways utilized for DHT biosynthesis. For this purpose, we analyzed levels of androgen intermediate metabolites from the different pathways in the serum of AA and EA men with PrCa. We first determined the serum levels of cholesterol, an important precursor for Leydig/adrenal as well as de novo tumor T and DHT synthesis ${ }^{4}$. The median levels of non-esterified cholesterol in the serum was similar between AA $(n=38)$ and EA $(n=69)$ men with PrCa in Roswell Park Cohort 2 (Table 1). This was consistent with our RNA-sequencing analyses of Roswell Park Cohort 1 that did not detect differences in the expression of enzymes that are essential for cholesterol synthesis, including Farnesyl-Diphosphate Farnesyltransferase 1 (FDFT1) and Squalene monooxygenase (SQLE), in PrCa and adjacent non-tumor tissues from AA and EA men (Supplementary Figure 2). This observation combined with the correlations between DHT and the expression of enzyme genes in the alternative pathways also provided confidence in measuring levels in the serum as surrogates for tissue production of androgen metabolites. 
Significant differences in T but not non-esterified cholesterol and DHT levels in the serum of $A A$ and EA men can possibly reflect the choice of pathways downstream from cholesterol utilized for DHT synthesis. Alternatively, it is possible that DHT might not be further converted to another downstream metabolite. We tested the first scenario by comprehensively measuring the levels of intermediate metabolites produced during DHT and $T$ biosynthesis ${ }^{1,29,30}$ in the serum of $A A(n=38)$ and EA $(n=69)$ men with PrCa in Roswell Park Cohort 2 (Supplementary Table 1). The grey highlighted box in Supplementary Figure 3 depicts the primary androgen synthesis pathway, 29, 30. Although we can't be certain of where these intermediate metabolites are produced, AA men with PrCa had an increased frequency of low levels of pregnenolone in the serum compared to EA men with $\mathrm{PrCa}(65.8$ vs. $42 \%, \mathrm{p}<0.05)$ (Supplementary Table 11). This was reflected in the median levels of pregnenolone which was significantly lower in the serum of AA compared to EA men with $\operatorname{PrCa}(p<0.01)$ (Table 1). Additionally, AA men with PrCa were more likely to have low levels of hydroxy pregnenolone (63.2 vs $43.5 \%$, $\mathrm{p}=0.069$ ) and DHEA (63 vs $44 \%, \mathrm{p}=0.071$ ), compared to EA men with PrCa (Table 1, Supplementary Table 11). The median levels of ASD, a final and penultimate metabolite before conversion to $\mathrm{T}$ and $\mathrm{DHT}$, respectively ${ }^{1,29,30}$, was lower, but not significant, in the serum of AA compared to EA men with PrCa (Table 1, Supplementary Table 11). Our data demonstrate that AA men with $\mathrm{PrCa}$ exhibit lower serum levels of intermediate metabolites generated from the primary pathway for DHT and T synthesis.

We next measured the levels of intermediate metabolites produced through the alternate pathways of DHT and T biosynthesis in the serum of AA and EA men with PrCa. Pregnenolone can be converted to $\mathrm{T}$ and $\mathrm{DHT}$ through an intermediate progesterone 
conversion step ${ }^{1,29,30}$. Significantly, the median levels of progesterone $(p<0.01)$ and its associated metabolites, including 17a-OH-progesterone $(p<0.05)$, cortisol $(p<0.01), 20 \alpha-$ dihydro-progesterone $(p<0.01)$ and corticosterone $(p<0.01)$ were lower in AA men compared to EA men with PrCa in Roswell Park Cohort 2 (Figure 5, Table 1). Progesterone can be converted to ASD and to AND that leads to DHT synthesis through 5a-dione (Supplementary Figure 3). The median levels of AND in the serum were similar between AA men and EA men with PrCa (Table 1). Significantly, AND levels were positively correlated to DHT levels only in the serum of AA men with PrCa (Supplementary Figure 4). These data suggest that DHT levels in the serum can be a surrogate indicator of AND levels in the serum of AA men with PrCa. AND can be converted to epiandrosterone that is further sulfated to act as a reserve for DHT production $^{50}$. The median levels of epiandrosterone in the serum were similar between the two racial groups (Table 1). Overall, we find lower levels of progesterone related metabolites in AA men with PrCa and similar levels of AND in AA and EA men with PrCa. These data provide evidence that AA men with PrCa are more likely to use an alternate progesterone pathway for DHT biosynthesis.

\section{Serum aldosterone levels are associated with West African ancestry markers}

Aldosterone is one of the terminal metabolites in the progesterone-corticosterone biosynthesis pathway. We found that aldosterone $(p<0.01)$ levels in the serum were above the limit of detection in a subset of AA men with PrCa in Roswell Park Cohort 1 (Table 1). Significantly, we did not detect aldosterone in the any of the serum samples in the Roswell Park Cohort 2 of EA men with PrCa (Table 1). Surprisingly, we found that aldosterone levels in the serum positively correlated with AIMs associated with West 
African ancestry (Figure 6A). We initially performed ancestry informative markers (AIMs) analysis to determine concordance between self-reported race and AIMs for a subset of men referred to as Roswell Park Cohort 3 (Supplementary Table 1). There was a direct correlation between self-reported race and AIMs in most of the clinical samples in Roswell Park Cohort 3 (Supplementary Table 1 and 12). With the observation of positive correlation with AIMs and aldosterone levels in the serum, we next determined if there are any differences in CYP11B enzymes that regulate corticosterone to aldosterone conversion $^{51}$. Examination of exome sequencing analyses in a separate set of AA and EA men with PrCa (Roswell Park Cohort 4, Supplementary Table 1) revealed that AA men with PrCa had a significantly higher frequency of multiple single nucleotide polymorphisms (SNPs) in the genes encoding CYP11B1 and CYP11B2 (Figure 6B-C, Supplementary Table 13). Furthermore, two SNPs, rs5313 and rs4544, located in the exon region of CYP11B2 have the potential to affect CYP11B2 function (Figure 6B-C, Supplementary Table 13). Therefore, it is possible that AA men with SNPs in the CYP11 family of enzymes may more readily convert corticosterone to aldosterone. Limited numbers of overlapping samples between Roswell Park Cohorts 2 and 4 prevented such correlation analyses. Overall, our data indicates that AA men with PrCa can have increased frequency of certain SNPs that can alter aldosterone synthesis.

\section{Serum androgen and metabolites are indicators of progression-free survival and RP failure in a race-specific manner}

It is unknown whether intermediate metabolites produced during DHT and T synthesis are indicators of clinical outcomes in PrCa. Therefore, we investigated whether levels of $\mathrm{DHT} / \mathrm{T}$ and related intermediate metabolites in the serum (high vs. low) can be 
indicators of early disease-progression and whether this is a race-specific indicator in Roswell Park Cohort 2. Overall survival, progression-free survival (PFS) and RP failure (RPF) were similar between AA and EA men with PrCa in Roswell Park Cohort 2 (Supplementary Figure 5). RPF is defined as the time from surgery until persistent disease, disease progression, subsequent treatment, death from $\mathrm{PrCa}$, or last follow-up. The metabolite levels were dichotomized into low $\left(<50^{\text {th }}\right.$ percentile) and high $\left(>50^{\text {th }}\right.$ percentile) based on the median value of the pooled samples or into 'below lower limit of quantitation' (BLQ) and detectable (i.e. >BLQ). Since the levels of each metabolite in the serum varied, each metabolite had a different cut-off for dichotomization for survival analyses. Both AA and EA men with PrCa had an equal distribution of high and low levels of non-esterified cholesterol in the serum (Table 1, Supplementary Table 11). We found that low levels of non-esterified cholesterol were associated with an increased incidence of 3- $(p<0.01)$ and 5-years RPF $(p<0.05)$ in pooled analyses of both AA and EA men with PrCa (Figure 7, Supplementary Table 14). Thus, non-esterified cholesterol levels in the serum are a potential indicators of early disease progression in a race-independent manner. AA men with PrCa more frequently had lower levels of $A S D$ in the serum compared to EA men (65.8 vs. 42\%, p<0.05) (Supplementary Table 11). In our pooled analyses, men with PrCa and low levels of ASD in the serum had increased incidence of 3-year RPF compared to men with PrCa and high levels of ASD (Figure 7, Supplementary Table 14). In the progesterone-cortisone pathway, AA men with $\operatorname{PrCa}$ had increased frequency of low levels of $17 \alpha-\mathrm{OH}$-progesterone (68.4 vs. $40.6 \%, \mathrm{p}<0.01)$ and progesterone $(71.1$ vs. $39.1 \%, \mathrm{p}<0.01)$ in the serum compared to EA men with $\mathrm{PrCa}$ (Supplementary Table 11). Men with low levels of $17 \alpha-\mathrm{OH}$-progesterone in the serum 
had significantly reduced 3-year, 5-year, and long-term RPF $(p<0.05)$ compared to men with high levels of 17a-OH-progesterone (Figure 7, Supplementary Table 14). Similarly, men with low levels of progesterone had lower 5-year $(p<0.05)$ and long term RPF $(p=0.06)$ compared to men with high levels of progesterone (Figure 7, Supplementary Table 14). Additionally, low levels of other progesterone-derived metabolites, deoxycorticosterone and corticosterone in the serum, were both indicators of low 5-year RPF in a race-independent manner (Figure 7, Supplementary Table 14). Overall, our results indicate that low levels of a subset of intermediate metabolites generated during DHT and T synthesis are found more commonly in AA men with PrCa and could be prognostic indicators of early disease progression.

\section{Androgen receptor expression and activity is associated with DHT levels and PrCa tumor stage in AA men}

Since we observed lower levels of $\mathrm{T}$ but not $\mathrm{DHT}$ in the serum in AA men with PrCa, we determined whether these levels are correlated with AR expression and transcriptional activity in both PrCa and adjacent non-tumor tissue of AA and EA men. First, we determined the percentage of positive AR nuclei in PrCa and adjacent non-tumor tissues, and their relationship to clinicopathological parameters in AA $(n=92)$ and EA $(\mathrm{n}=95)$ men in tissue microarrays (TMAs) Roswell Park Cohort 5 (Supplementary Table 1, Demographics in Supplementary Table 15). In agreement with previous results ${ }^{52}$, the percentage of positive AR nuclei was significantly higher in adjacent non-tumor tissues (Supplementary Figure 6), but not different between tumor tissues, from AA compared to EA men (mean: 78.20 vs. $73.28, p<0.01$ ) (Table 2, Supplementary Figure 6). In the pooled analyses of Roswell Park Cohort 5, no significant differences in the percentage of 
positive AR nuclei in PrCa tissue or non-tumor tissue adjacent to PrCa between PrCa with Gleason scores $<=3+4$ and $>=4+3$ were detected (Table 2). However, when race specific differences were determined, we observed that the percentage of positive AR nuclei were lower in AA than EA men (mean: 75.19 vs. 78.82, $p=0.07$ ) in PrCa with Gleason score $>=4+3$ (Table 2). By contrast, the percentage of positive AR nuclei was higher in adjacent non-tumor tissues in AA compared to EA men with Gleason score >= 4+3 (mean: 80.15 vs 71.31) (Table 2). Surprisingly, AA men who did not receive hormone therapies had a significantly higher percentage of positive AR nuclei compared to AA men who received hormone therapies (80.45 vs 68.78, $\mathrm{p}<0.001$ ) (Table 2). Combined, our data suggest that AR protein expression in both adjacent non-tumor and PrCa tissues are indicators of higher Gleason score only in AA men with PrCa.

We next investigated whether the percentage of positive AR nuclei in PrCa was correlated with $\mathrm{T}$ and DHT levels in the serum by utilizing a subset of clinical samples that overlapped in Roswell Park Cohorts 2 and 5 (Supplementary Table 1). DHT levels in the serum of all men trended towards a negative correlation with percentage of positive AR nuclei in adjacent non-tumor tissues of AA but not EA men ( $r=-0.21$ vs $r=0.09)$ (Supplementary Figure 7). However, $\mathrm{T}$ levels in the serum trended towards negative association with the percentage of positive AR nuclei in adjacent non-tumor tissues in both $\mathrm{AA}$ and EA men with PrCa ( $r=-0.14$ vs $r=-0.03)$ (Supplementary Figure 7). In PrCa tissues, the percentage of positive AR nuclei trended towards a negative correlation with DHT and T levels in the serum of both AA and EA men PrCa (Supplementary Figure 7). The lower $r$ values in the correlation analyses could be a result of lower availability of overlapping clinical samples for both serum metabolite and AR protein expression 
analyses, and thus, should be interpreted with caution. Nevertheless, these results underscore the importance of further characterization of androgens and intermediate metabolites in the serum along with AR gene and protein level data in a larger cohort of clinical samples.

Finally, we determined if T and DHT levels in the serum correlate with AR activity in adjacent non-tumor and PrCa tissues in a race-specific manner. We first observed the levels of SHBG, a protein that binds $\mathrm{T}$ and $\mathrm{DHT}$ to reduce the levels of circulating bioavailable androgens, in the serum of $\mathrm{AA}$ and $\mathrm{EA}$ men with $\mathrm{PrCa}^{53}$. Previous studies have shown that SHBG levels in the serum are variable in $A A$ and $E A$ populations regardless of whether these men are healthy or have $\mathrm{PrCa}^{17,32,54-61}$. In our study, the median levels of SHBG in the serum were similar between AA and EA men with PrCa (Table 1). Moreover, SHBG levels were positively correlated to T and DHT in all clinical samples (Supplementary Figure 4). These data suggest that the bioavailable levels of DHT can potentially be similar between AA and EA men. Next, we investigated a subset of patient specimens that were analyzed for both RNA sequencing (Roswell Park Cohort 3) and serum metabolite measurements (Roswell Park Cohort 1) (AA n=8, EA n=11) (Supplementary Table 1). For AR activity, we measured RNA levels of the established AR transcriptional targets $K L K 2, K L K 3, N K X 3.1$, and TMPRSS2 that have consistently validated as AR transcriptional targets in multiple studies ${ }^{62-65}$. We utilized the GSVA approach to develop a score based on RNA expression of these four target genes. There was insufficient power to compare AR activity between clinical samples with low and high levels of $\mathrm{T}$ and $\mathrm{DHT}$, as well as AR protein expression, due to the limited number of overlapping samples between RNA sequencing and serum metabolite analyses. 
However, we found that DHT levels in the serum correlated with AR activity in AA men, but not EA men, with PrCa (Figure 8). DHT levels in the serum of AA men with $\mathrm{PrCa}$ trended toward a positive correlation with AR activity in PrCa tissues (Figure 8). There was a significant correlation $(r=0.75, p<0.05)$ when $R N A$ expression in $\mathrm{PrCa}$ tissues was normalized to RNA expression in adjacent non-tumor tissues (Figure 8). Overall, our results indicate that DHT levels in the serum reflected AR transcriptional activity only in PrCa from AA men. 


\section{Discussion}

Our studies show that overexpression of enzymes from alternate pathways in androgen synthesis in therapy naïve RP tissues correlates with DHT levels in the serum only in AA men. These data suggest that changes in the androgen synthesis pathway is an early occurrence in PrCa in $\mathrm{AA}$ men. It is vital that androgen and intermediate metabolite measurements in the serum are conducted using reliable and sensitive technologies. We used the LC-MS/MS technique ${ }^{49}$, which is sensitive and specific, to identify race-specific differences in the levels of androgens and several intermediate androgen metabolites. The LC-MS/MS approach based on mass and time of elution accurately predicts the presence of a particular androgen related metabolite in the given sample. The use of LC-MS/MS could also be a reason for discrepant results from previously published reports that use relatively less sensitive chemiluminescent assays and radioimmunoassays ${ }^{18,45,66,67}$. Our measurements were performed in serum, although PrCa itself can produce androgens ${ }^{25,} 31,32,49,68$. There are reports of racespecific differences in levels of intermediate androgen metabolites, but neither T nor DHT levels in PrCa tissues in the castration recurrent setting $25,31,32,49,68$. Future studies that measure the levels of androgens in therapy naïve PrCa tissues and serum from the same clinical cohort will be important to understand the relationship between androgens in circulation and in tissues.

Our pooled data show that lower levels of $\mathrm{T}$ and $\mathrm{DHT}$ in the serum are associated with high Gleason score PrCa. Roswell Park Cohort 2 has a higher percentage of AA men with PrCa with Gleason score $>7$ compared to EA men. Therefore, there are two possible explanations for these data. The first is that AA men with PrCa with Gleason score $>7$ are 
more likely to have lower serum T levels than EA men with PrCa with Gleason score >7. Another explanation would be that Gleason score is a potential confounding factor. A multivariate analysis is required to address this, but the analysis of a greater number of clinical samples needs to be done to confirm this hypothesis. Our studies also show that mean T levels but not DHT levels in the serum are significantly lower in AA men with PrCa, whereas mean SHBG levels are similar between AA and EA men with PrCa. Based on our findings and what is known about SHBG $48,69,70$ and its impact on circulating hormones, bioavailable $T$ in tissues may be even lower in AA compared to EA men with PrCa. A rapid fall in levels of $\mathrm{T}$ in the serum which would lower bioavailable $\mathrm{T}$ are more commonly observed in healthy AA men, and this rapid fall is associated with PrCa risk ${ }^{17}$, $18,54,55,58,59,71-73$. It is important to note that this study focused on serum that was obtained at the time of PrCa diagnosis and we did not investigate serum levels of androgens and intermediate metabolites either before disease diagnosis or throughout the disease continuum. An ideal future study would follow the same cohort of patients and assess if there are race-specific associations between levels of DHT and T in serum at multiple points with PrCa progression. It is counterintuitive that rapid falls in $\mathrm{T}$ levels during castration and potentially androgen deprivation therapies could contribute to $\mathrm{PrCa}$ progression. Whether targeting androgen metabolism earlier in the PrCa continuum would also cause a dramatic fall in DHT/T levels, and therefore lead to rapid disease progression, remains to be investigated.

Interestingly, our pooled analyses revealed that lower levels of several intermediate metabolites were associated with lower time to RPF, thus suggesting these are indicators of early disease progression. Additionally, AA men with PrCa more often 
present with lower levels of these metabolites in serum. Overall survival, PFS and RPF were similar between AA and EA men in the Roswell Park clinical cohorts. Therefore, we provide a rationale for measuring the intermediate metabolites, in addition to DHT and T, in the serum and possibly PrCa tissues and determining their utility as race-specific biomarkers in a larger cohort of PrCa patients. We also discovered higher frequency of novel germline SNPs in the genes encoding CYP11B family of enzymes in AA men with PrCa. The SNPs we report are either missense variants or variants that can possibly affect the coding sequence of CYP11B2, and ultimately affect its function. The CYP11B family of enzymes mediate corticosterone to aldosterone conversion ${ }^{51}$. We find that only a subset of AA men with PrCa have aldosterone levels that are above the limit of detection in serum. Further studies in larger cohorts of different racial groups are needed to establish the causal relationship between the SNPs observed in CYP11B2-encoding genes and corticosterone-aldosterone conversion. These studies can also determine whether SNPs in CYP11B enzymes can be used as potential race-specific biomarkers in a larger cohort of PrCa patients.

Circulating $\mathrm{T}$ and DHT from the serum that either actively or passively diffuse through the tissue can maintain AR nuclear translocation and thus transcriptional activity in both PrCa and adjacent non-tumor tissues $48,69,70,74,75$. In addition, DHT has a greater affinity and slower rate of dissociation from $\mathrm{AR}^{76-79}$. Our data that shows similar levels of DHT in the serum suggest that DHT-mediated AR transcriptional activity may be similar between AA and EA men. Although DHT and T are thought to be the primary ligands for $A R$, intermediate metabolites produced during androgen synthesis also have some affinity to $A R^{1,2,80}$. The affinity of intermediate androgen metabolites are several fold lower 
than $\mathrm{T}$ and $\mathrm{DHT}^{1,2,80}$, and it is more likely that they are rapidly metabolized into $\mathrm{T}$ and DHT for AR binding and transcriptional activation ${ }^{79}, 81$. Further studies of appropriate models are needed to determine whether intermediate androgen metabolites can bind to $\mathrm{AR}$ and initiate its nuclear translocation in human PrCa and non-tumor cells. These studies may help identify alternative mechanisms for maintaining AR transcriptional activity that sustains PrCa growth, and result in differences in clinical outcomes in AA and EA men.

We found that the percent of AR-positive nuclei was significantly lower in Gleason score $>=4+3$ PrCa tissue at the time of RP in AA compared to EA men. However, the percentage of AR-positive nuclei was greater in adjacent non-tumor tissue of Gleason score $>=4+3$ PrCa in AA compared to EA men. In addition, DHT levels in the serum were positively correlated to AR transcriptional activity only in AA men. Therefore, our results suggest that increased AR nuclear expression in adjacent non-tumor tissue of AA men may support AR transcriptional activity for the nearby PrCa cells. There is evidence for a field effect that influences molecular changes in the tissues surrounding $\mathrm{PrCa}^{82,83}$. In support of this hypothesis, previous studies observed that paracrine signaling by stromal AR promotes proliferation and invasion of PrCa cells in vitro ${ }^{84,85}$. This finding warrants additional studies in preclinical models of adjacent non-tumor and PrCa tissues isolated from men of different races to delineate the role of paracrine AR signaling in $\mathrm{PrCa}$. Furthermore, the validation of our results in larger cohorts of primary PrCa may support the use of serum DHT levels as a surrogate marker for AR activity in treatment naïve AA men with PrCa. 
To summarize, our results provide a rationale for moving treatments targeting androgen metabolizing enzymes and AR transcriptional activity earlier in the disease continuum, even in the treatment naïve setting for AA men with PrCa. In the era of personalized and precision medicine, our study along with other ongoing efforts ${ }^{86-90}$, emphasize the need to include underrepresented racial groups to understand and develop better prognostic and diagnostic indicators in the PrCa disease continuum. 


\section{Methods}

All the clinical samples included in Roswell Park Cohorts 1-5 were collected with informed consent at the time of radical prostatectomy at Roswell Park. Except for one patient in Roswell Park Cohort 1, all the samples were obtained prior to any treatment. The samples were de-identified before the analyses.

RNA-sequencing, GSVA scoring and $q P C R$

Paired-end RNA sequencing was performed using RNA isolated from clinical samples. Pathway enrichment programs including Genego from Metacore were used to identify differentially expressed pathways between AA and EA men with PrCa. GSVA scoring was performed using the GSVA R package. GSVA scores were built on sSGSEA using a nonparametrical approach and a KS-like random walk statistic after normalizing gene expression profiles with an appropriate kernel estimation function depending on whether the expression levels were continuous or counted data. The enrichment scores compared the overall expression of two samples within the same gene-set. Given a gene-set, samples with positive enrichment values have more genes at the top the rank expression levels than samples whose genes have lower levels (for example: the bottom of the ranked expression list) with respect to the gene-set. For QPCR validation, 500ng of RNA from clinical samples were converted to cDNA using the iScript cDNA synthesis kit from Biorad (Catalog number: 1708891). Primers that overlapped intron-exon junction were designed using the NCI Primer-blast software and are listed in Supplementary Table 13. iTaq SYBR green kit from Biorad (Catalog number 1725121) was utilized for qPCR reactions performed on a Biorad CFX machine. The values normalized to GAPDH are presented for each primer set in PrCa and adjacent non-tumor tissues. 


\section{Metabolism pipeline}

The metabolism pipeline was performed on the Roswell Park and TCGA PrCa cohorts ${ }^{47}$.

\section{LC-MS/MS and statistics}

Study samples were analyzed for androgens (T, DHT, DHEA, ASD, AND, and 5a-dione) using a validated high pressure liquid chromatographic assay with tandem mass spectral detection (LC-MS/MS) ${ }^{49}$. Immediately after the androgen analysis, the extracted samples were re-injected using a semi-quantitative targeted metabolomics approach to examine an additional 26 compounds within the steroidogenesis pathway from cholesterol to estrogens. Serum samples were quantitated using human serum calibration and quality control (QC) samples prepared by spiking known amounts of androgens into charcoalstripped female human serum (Bioreclamation). The concentration range of the calibrators and QCs are presented in Supplementary Table 8. Liquid/liquid sample extractions were performed by mixing a $250 \mu \mathrm{L}$ aliquot of a serum calibrator, $\mathrm{QC}$, matrix blank, or study sample with LC/MS-grade water, internal standard (IS) solution (75.0/225 $\mathrm{pg} / \mathrm{mL} \mathrm{d} \mathrm{d}_{3}-\mathrm{T} / \mathrm{d}_{3}-\mathrm{DHT}$ in $75 \%$ methanol), and $4.0 \mathrm{~mL}$ of methyl-tert-butyl ether (MTBE, EMD Millipore, Billerica, MA) in a $13 \times 100 \mathrm{~mm}$ glass screw-top tube. Tubes were capped with teflon-lined caps, vortexed, rotated for $15 \mathrm{~min}$ at room temperature, and then centrifuged (Heraeus Multifuge X3R, Thermo Scientific) at $2,800 \mathrm{rpm}$ and $4{ }^{\circ} \mathrm{C}$ for $15 \mathrm{~min}$ to separate liquid phases. The aqueous phase was frozen in a dry ice/acetone bath and the MTBE layer was poured into a clean $13 \times 100 \mathrm{~mm}$ glass conical tube. The MTBE was evaporated at $37^{\circ} \mathrm{C}$ under nitrogen and the residue was reconstituted with $60.0 \mu \mathrm{L}$ of $60 \%$ methanol. The resulting suspensions were centrifuged (Heraeus Multifuge X3R, Thermo Scientific) 
at $2,800 \mathrm{rpm}$ at $4^{\circ} \mathrm{C}$ for $5 \mathrm{~min}$ to separate insoluble materials. The clear supernatant was transferred to an autosampler vial and a $7-15 \mu \mathrm{L}$ aliquot was injected.

LC-MS/MS analyses of the extracted samples was be performed using a Prominence UFLC System (Shimadzu Scientific Instruments, Kyoto, Japan), a QTRAP® 5500 mass spectrometer (AB Sciex, Framingham, MA), with an electrospray ionization source, and two 10-port switching valves (Valco instruments Co. Inc., Houston, TX, model EPC10W). Chromatographic separation is achieved using a Phenomenex Luna C18(2) column (part number 00F-4251-B0) preceded by a Phenomenex SecurityGuard cartridge (C18, part number AJ0-4286), which were maintained at $60{ }^{\circ} \mathrm{C}$ and a flow rate of $175 \mu \mathrm{L} / \mathrm{min}$. Chromatography was performed using a biphasic gradient (Mobile Phase A: 65\% methanol containing $0.400 \mathrm{ml}$ of $1.00 \mathrm{M}$ ammonium formate and $62.0 \mu \mathrm{l}$ of concentrated formic acid per liter; and Mobile Phase B: $100 \%$ methanol with $0.400 \mathrm{ml}$ of $1.00 \mathrm{M}$ ammonium formate and $62.0 \mu \mathrm{l}$ of concentrated formic acid per liter). After the standard androgen analysis, each sample was re-injected under a different set of gradient conditions to perform semi-quantitative analysis of the steroidogenesis pathway. Analytes were detected using multiple reaction monitoring (MRM) in positive ion mode controlled by $A B$ Sciex Analyst ${ }^{\circledR}$ software, version 1.6.2. Mass spectrometer conditions for androgens were ion spray voltage 5,250 volts, turbo gas temperature $700{ }^{\circ} \mathrm{C}$, gas $1=65$, gas $2=60$, curtain gas 20, collision-associated dissociation (CAD) gas = medium. Q1 and Q3 were set at unit mass resolution, and nitrogen was used for all gases. Voltages for maximum parent/fragment ion pair intensities were optimized using direct infusion and flow injection analysis. Minor modifications in the operating conditions were performed to maintain optimal sensitivity. 
Calibration curves were generated using analyte/IS peak area response ratios versus nominal concentrations $(\mathrm{ng} / \mathrm{mL})$ and weighted linear regressions using a weighting factor 1/concentration ${ }^{2}$. $d_{3}-T$ was used as the IS for T, ASD and DHEA, and $d_{3}$-DHT for DHT and AND. Back-calculated concentrations were generated using the formula $x=(y-b) / m$, where $\mathrm{x}$ is the back-calculated concentration, $\mathrm{y}$ is the analyte/IS peak area ratio, $\mathrm{b}$ is the $y$-intercept and $m$ is the slope. Calibrator and quality control acceptance criteria follow FDA bioanalytical guidelines whereby all acceptable concentrations must have accuracy deviations of $\leq \pm 15 \%$ from the nominal concentration with relative standard deviations (\% RSD) $\leq 15 \%$ except at the lower limit of quantitation (LLOQ), where $\leq 20 \%$ deviations were allowed for both parameters. Performance data from the analysis of 855 human serum samples is provided in Supplementary Table 9.

The patient characteristics were summarized by race or age groups using the mean, median, and standard deviation for continuous variables; and using frequencies and relative frequencies for categorical variables (Supplementary Tables 2, 7 and 15). Comparisons were made using the Mann-Whitney $U$ or Pearson chi-square tests, as appropriate. The androgen metabolites were summarized by race or age group using the mean, median, and standard deviation. To account for some observations that were BLQ, the mean and standard deviation were estimated in SAS using the maximum likelihood approach described by Croghan and Egeghy ${ }^{91}$. The metabolite levels were compared using a left censored version of the log-rank test. The association between metabolite levels and other patient characteristics were evaluated using these methods. The timeto-event outcomes were summarized by race or age group using standard Kaplan-Meier methods and compared using the standard log-rank test. Overall survival (OS) was 
defined as the time from surgery until death due to any cause or last follow-up. Progression-free survival (PFS) was defined as the time from surgery until recurrence, death due to PrCa, or last follow-up. PFS is not calculated for patients with persistent disease. Freedom from radical prostatectomy failure (RPF) was defined as the time from surgery until persistent disease, disease progression, subsequent treatment, death from PrCa, or last follow-up. The metabolite levels were dichotomized into low $(<50$ th percentile) and high (> 50th percentile) with the median cut-off values, determined in the pooled samples, included in the $<50$ percentile group or into BLQ and detectable (i.e. $>B L Q)$. The time-to-event outcomes were summarized for the categorized metabolite levels using standard Kaplan-Meier methods and log-rank tests. All analyses were conducted in SAS v9.4 (Cary, NC) at a significance level of 0.05 .

\section{AIMs and SNPs}

AIMs analysis was performed by Dr. Kittles group ${ }^{92}$. The association between AIMs and levels of androgens and intermediate metabolites in the serum were measured using Spearman correlation analysis. Best practices for germline variant calling with GATK was followed to identify the SNPs using blood whole exome data. The variants that passed the filter were kept for the association studies between race and AR metabolic genes. Fisher exact test was applied to the variants and $p$-values of less than 0.05 were considered statistically significant.

Immunohistochemistry, Image $\mathrm{J}$ quantitation and statistics

TMA slides were stained with an AR antibody (Agilent, \#M3562) and digitally scanned using Aperio Scanscope. Individual PrCa images were captured using Scanscope and 
the ImmunoRatio plugin (ImageJ, NIH) was used to analyze the percentage of positive AR nuclei in each clinical sample. Patient demographic and clinical characteristics for all the samples were analyzed using the mean and standard deviation for continuous variables and frequencies and relative frequencies for categorical variables. The patient demographic and clinical characteristics were compared between racial groups (EA versus $A A$ ) or age groups (<55 versus $>=55$ ) using the Mann-Whitney $U$ and Fisher's exact tests for continuous and categorical variables, respectively. For each patient characteristic, the AR scores and ratios were modeled as a function of the patient characteristic, race or age, and their interaction using a general linear model. F-tests about the appropriate linear combination of model estimates were used to test for: A) the association between the patient characteristic and AR within each race or age group; and B) the race or age effect on the association between AR and the patient characteristic (ie. testing the interaction term). All analyses were completed in SAS v9.4 (Cary, NC) at a significance level of 0.05 . A p-value less than 0.05 denoted a statistically significant result. 


\section{Author contributions}

Conceived and designed experiments and wrote the manuscript: SR, AW; Discussed the data and revised the manuscript: SR, AW, ECG, KA, JW, SRR, DJS, GA, JLM, WJH, RAK; Performed experiments: SR, AW, RAK; Analyzed the data: SR, AW, ECG, KA, JW, SRR, GA, RAK; Contributed reagents/materials/analysis tools: SR, AW, ECG, KA, JW, SRR, DJS, JLM, WJH, RAK. All authors read and approved the final manuscript. 


\section{Acknowledgments}

We thank Dr. John Wilton, Director of the BMPK Resource ran and analyzed the serum samples for androgens and their related metabolites. We also thank Zara Kazmierczak for performing the validation of enzymes involved in androgen synthesis in clinical samples. This work was supported by: DoD Health Disparity Research Award (W81XWH17-1-0115) to Dr. Woloszynska; Roswell Park Alliance Foundation Award to Dr. Huss. Clinical data delivery and Honest Broker services for this study were provided by the Biomedical Data Science Shared Resource. The work was also supported by the following Shared Resources: Bioanalystics, Metabolomics and Pharmacokinetics; Bioinformatics; Biostatistics; Data Bank and BioRepository Genomics and Pathology Network. The support for the Shared Resources cores are funded by the National Cancer Institute (NCI P30CA16056). 


\section{References}

1. Dai C, Heemers H, Sharifi N. Androgen Signaling in Prostate Cancer. Cold Spring Harbor Perspectives in Medicine 2017; 7.

2. Heinlein CA, Chang C. Androgen Receptor in Prostate Cancer. Endocrine Reviews $2004 ; 25: 276-308$.

3. Lonergan PE, Tindall DJ. Androgen receptor signaling in prostate cancer development and progression. Journal of carcinogenesis $2011 ; 10: 20-$.

4. Fiandalo MV, Wu W, Mohler JL. The role of intracrine androgen metabolism, androgen receptor and apoptosis in the survival and recurrence of prostate cancer during androgen deprivation therapy. Current drug targets 2013; 14:420-40.

5. Wright ME, Tsai MJ, Aebersold R. Androgen receptor represses the neuroendocrine transdifferentiation process in prostate cancer cells. Molecular endocrinology (Baltimore, Md) 2003; 17:1726-37.

6. Berger R, Febbo PG, Majumder PK, Zhao JJ, Mukherjee S, Signoretti S, Campbell KT, Sellers WR, Roberts TM, Loda M, et al. Androgen-Induced Differentiation and Tumorigenicity of Human Prostate Epithelial Cells. Cancer research 2004; 64:8867-75.

7. Darshan MS, Loftus MS, Thadani-Mulero M, Levy BP, Escuin D, Zhou XK, Gjyrezi A, Chanel-Vos C, Shen R, Tagawa ST, et al. Taxane-Induced Blockade to Nuclear Accumulation of the Androgen Receptor Predicts Clinical Responses in Metastatic Prostate Cancer. Cancer research 2011; 71:6019-29.

8. Sun G, Chen X, Gong u, Chen Y, Li G, Wei F, Jiang A, Niu Y, Shang Z. Androgen deprivation therapy with chemotherapy or abiraterone for patients with metastatic 
hormone-naive prostate cancer: a systematic review and meta-analysis. Future Oncology 2019; 15:1167-79.

9. Vander Griend DJ, Litvinov IV, Isaacs JT. Conversion of androgen receptor signaling from a growth suppressor in normal prostate epithelial cells to an oncogene in prostate cancer cells involves a gain of function in c-Myc regulation. Int J Biol Sci 2014; 10:627-42.

10. Zarif JC, Lamb LE, Schulz VV, Nollet EA, Miranti CK. Androgen receptor nonnuclear regulation of prostate cancer cell invasion mediated by Src and matriptase. Oncotarget 2015; 6:6862-76.

11. Zhu M-L, Horbinski CM, Garzotto M, Qian DZ, Beer TM, Kyprianou N. Tubulintargeting chemotherapy impairs androgen receptor activity in prostate cancer. Cancer research 2010; 70:7992-8002.

12. Wang B-D, Yang Q, Ceniccola K, Bianco F, Andrawis R, Jarrett T, Frazier H, Patierno SR, Lee NH. Androgen receptor-target genes in african american prostate cancer disparities. Prostate Cancer 2013; 2013:763569-.

13. Ali HEA, Lung P-Y, Sholl AB, Gad SA, Bustamante JJ, Ali HI, Rhim JS, Deep G, Zhang J, Abd Elmageed ZY. Dysregulated gene expression predicts tumor aggressiveness in African-American prostate cancer patients. Scientific reports 2018; 8:16335.

14. Schatzl G, Madersbacher S, Thurridl T, Waldmüller J, Kramer G, Haitel A, Marberger M. High-grade prostate cancer is associated with low serum testosterone levels. The Prostate 2001; 47:52-8. 
15. Gao F, Li G, Liu C, Gao H, Wang H, Liu W, Chen M, Shang Y, Wang L, Shi J, et al. Autophagy regulates testosterone synthesis by facilitating cholesterol uptake in Leydig cells. Journal of Cell Biology 2018; 217:2103-19.

16. Sharifi N, McPhaul MJ, Auchus RJ. "Getting From Here to There"-Mechanisms and Limitations to the Activation of the Androgen Receptor in Castration-Resistant Prostate Cancer. Journal of Investigative Medicine 2010; 58:938-44.

17. Litman HJ, Bhasin S, Link CL, Araujo AB, McKinlay JB. Serum androgen levels in black, Hispanic, and white men. The Journal of clinical endocrinology and metabolism 2006; 91:4326-34.

18. Kubricht WS, 3rd, Williams BJ, Whatley T, Pinckard P, Eastham JA. Serum testosterone levels in African-American and white men undergoing prostate biopsy. Urology 1999; 54:1035-8.

19. Ross R, Bernstein L, Judd H, Hanisch R, Pike M, Henderson B. Serum testosterone levels in healthy young black and white men. Journal of the National Cancer Institute 1986; 76:45-8.

20. Ellis L, Nyborg H. Racial/ethnic variations in male testosterone levels: A probable contributor to group differences in health. Steroids 1992; 57:72-5.

21. Hofland J, van Weerden WM, Dits NFJ, Steenbergen J, van Leenders GJLH, Jenster G, Schröder FH, de Jong FH. Evidence of Limited Contributions for Intratumoral Steroidogenesis in Prostate Cancer. Cancer research 2010; 70:1256-64.

22. Ishizaki F, Nishiyama T, Kawasaki T, Miyashiro Y, Hara N, Takizawa I, Naito M, Takahashi K. Androgen deprivation promotes intratumoral synthesis of 
dihydrotestosterone from androgen metabolites in prostate cancer. Scientific reports 2013; 3:1528.

23. Montgomery RB, Mostaghel EA, Vessella R, Hess DL, Kalhorn TF, Higano CS, True LD, Nelson PS. Maintenance of intratumoral androgens in metastatic prostate cancer: a mechanism for castration-resistant tumor growth. Cancer research 2008; 68:4447-54.

24. Hearn JWD, Sweeney CJ, Almassi N, Reichard CA, Reddy CA, Li H, Hobbs B, Jarrard DF, Chen Y-H, Dreicer R, et al. HSD3B1 Genotype and Clinical Outcomes in Metastatic Castration-Sensitive Prostate Cancer. JAMA oncology 2020; 6:e196496-e.

25. Sharifi N. Minireview: Androgen Metabolism in Castration-Resistant Prostate Cancer. Molecular Endocrinology 2013; 27:708-14.

26. Karantanos T, Evans CP, Tombal B, Thompson TC, Montironi R, Isaacs WB. Understanding the mechanisms of androgen deprivation resistance in prostate cancer at the molecular level. European urology 2015; 67:470-9.

27. Allott EH, Howard LE, Aronson WJ, Terris MK, Kane CJ, Amling CL, Cooperberg MR, Freedland SJ. Racial Differences in the Association Between Preoperative Serum Cholesterol and Prostate Cancer Recurrence: Results from the SEARCH Database. Cancer epidemiology, biomarkers \& prevention : a publication of the American Association for Cancer Research, cosponsored by the American Society of Preventive Oncology 2016; 25:547-54.

28. Jamnagerwalla J, Howard LE, Allott EH, Vidal AC, Moreira DM, Castro-Santamaria R, Andriole GL, Freeman MR, Freedland SJ. Serum cholesterol and risk of high-grade 
prostate cancer: results from the REDUCE study. Prostate cancer and prostatic diseases $2018 ; 21: 252-9$

29. Mostaghel EA, Nelson PS. Intracrine androgen metabolism in prostate cancer progression: mechanisms of castration resistance and therapeutic implications. Best Pract Res Clin Endocrinol Metab 2008; 22:243-58.

30. Fiandalo MV, Wilton J, Mohler JL. Roles for the backdoor pathway of androgen metabolism in prostate cancer response to castration and drug treatment. Int J Biol Sci $2014 ; 10: 596-601$.

31. Marks LS, Hess DL, Dorey FJ, Macairan ML. Prostatic tissue testosterone and dihydrotestosterone in African-American and white men. Urology 2006; 68:337-41.

32. Mohler JL, Gaston KE, Moore DT, Schell MJ, Cohen BL, Weaver C, Petrusz P. Racial differences in prostate androgen levels in men with clinically localized prostate cancer. J Urol 2004; 171:2277-80.

33. Liu W, Liu R, Wang L. Androgen metabolism genes in prostate cancer health disparities. Cancer Health Disparities 2017; 1:e1-e6.

34. Thomae BA, Eckloff BW, Freimuth RR, Wieben ED, Weinshilboum RM. Human sulfotransferase SULT2A1 pharmacogenetics: genotype-to-phenotype studies. The Pharmacogenomics Journal 2002; 2:48-56.

35. Wilborn TW, Lang NP, Smith M, Meleth S, Falany CN. Association of SULT2A1 allelic variants with plasma adrenal androgens and prostate cancer in African American men. The Journal of Steroid Biochemistry and Molecular Biology 2006; 99:209-14. 
36. Powell IJ, Zhou J, Sun Y, Sakr WA, Patel NP, Heilbrun LK, Everson RB. CYP3A4 genetic variant and disease-free survival among white and black men after radical prostatectomy. J Urol 2004; 172:1848-52.

37. Bangsi D, Zhou J, Sun Y, Patel NP, Darga LL, Heilbrun LK, Powell IJ, Severson RK, Everson RB. Impact of a genetic variant in CYP3A4 on risk and clinical presentation of prostate cancer among white and African-American men. Urologic oncology 2006; 24:21-7.

38. Karypidis AH, Olsson M, Andersson SO, Rane A, Ekström L. Deletion polymorphism of the UGT2B17 gene is associated with increased risk for prostate cancer and correlated to gene expression in the prostate. The Pharmacogenomics Journal 2008; 8:147-51.

39. Zhu AZX, Cox LS, Ahluwalia JS, Renner CC, Hatsukami DK, Benowitz NL, Tyndale RF. Genetic and phenotypic variation in UGT2B17, a testosterone-metabolizing enzyme, is associated with BMI in males. Pharmacogenet Genomics 2015; 25:263-9.

40. Turgeon D, Carrier JS, Lévesque E, Hum DW, Bélanger A. Relative enzymatic activity, protein stability, and tissue distribution of human steroid-metabolizing UGT2B subfamily members. Endocrinology $2001 ; 142: 778-87$.

41. Price DK, Chau CH, Till C, Goodman PJ, Leach RJ, Johnson-Pais TL, Hsing AW, Hoque A, Parnes HL, Schenk JM, et al. Association of androgen metabolism gene polymorphisms with prostate cancer risk and androgen concentrations: Results from the Prostate Cancer Prevention Trial. Cancer 2016; 122:2332-40.

42. Chen WS, Feng EL, Aggarwal R, Foye A, Beer TM, Alumkal JJ, Gleave M, Chi $\mathrm{KN}$, Reiter RE, Rettig MB, et al. Germline polymorphisms associated with impaired 
survival outcomes and somatic tumor alterations in advanced prostate cancer. Prostate cancer and prostatic diseases 2020; 23:316-23.

43. Chang K-H, Li R, Papari-Zareei M, Watumull L, Zhao YD, Auchus RJ, Sharifi N. Dihydrotestosterone synthesis bypasses testosterone to drive castration-resistant prostate cancer. Proceedings of the National Academy of Sciences 2011; 108:13728-33. 44. Pierorazio PM, Ferrucci L, Kettermann A, Longo DL, Metter EJ, Carter HB. Serum testosterone is associated with aggressive prostate cancer in older men: results from the Baltimore Longitudinal Study of Aging. BJU Int 2010; 105:824-9.

45. Vijayakumar S, Quadri SF, Dong L, Ignacio L, Kathuria IN, Sutton H, Halpern H. Results of a study to correlate serum prostate specific antigen and reproductive hormone levels in patients with localized prostate cancer. J Natl Med Assoc 1995; 87:813-9.

46. Ryan CJ, Dutta S, Kelly WK, Middleberg R, Russell C, Morris MJ, Taplin ME, Halabi S. Androgens and Overall Survival in Patients With Metastatic Castration-resistant Prostate Cancer Treated With Docetaxel. Clinical genitourinary cancer 2019.

47. Rosario SR, Long MD, Affronti HC, Rowsam AM, Eng KH, Smiraglia DJ. Pancancer analysis of transcriptional metabolic dysregulation using The Cancer Genome Atlas. Nature communications 2018; 9:5330-.

48. Goldman AL, Bhasin S, Wu FCW, Krishna M, Matsumoto AM, Jasuja R. A Reappraisal of Testosterone's Binding in Circulation: Physiological and Clinical Implications. Endocrine Reviews 2017; 38:302-24.

49. Wilton JH, Titus MA, Efstathiou E, Fetterly GJ, Mohler JL. Androgenic biomarker profiling in human matrices and cell culture samples using high throughput, electrospray tandem mass spectrometry. The Prostate 2014; 74:722-31. 
50. Zang T, Taplin M-E, Tamae D, Xie W, Mesaros C, Zhang Z, Bubley G, Montgomery B, Balk SP, Mostaghel EA, et al. Testicular vs adrenal sources of hydroxy-androgens in prostate cancer. Endocrine-related cancer 2017; 24:393-404.

51. Strushkevich N, Gilep AA, Shen L, Arrowsmith CH, Edwards AM, Usanov SA, Park HW. Structural insights into aldosterone synthase substrate specificity and targeted inhibition. Mol Endocrinol 2013; 27:315-24.

52. Gaston KE, Kim D, Singh S, Ford OH, Mohler JL. Racial Differences in Androgen Receptor Protein Expression in Men With Clinically Localized Prostate Cancer. The Journal of Urology 2003; 170:990-3.

53. Stattin P, Lumme S, Tenkanen L, Alfthan H, Jellum E, Hallmans G, Thoresen S, Hakulinen T, Luostarinen T, Lehtinen M, et al. High levels of circulating testosterone are not associated with increased prostate cancer risk: A pooled prospective study. International Journal of Cancer 2004; 108:418-24.

54. Wu AH, Whittemore AS, Kolonel LN, John EM, Gallagher RP, West DW, Hankin J, Teh CZ, Dreon DM, Paffenbarger RS, Jr. Serum androgens and sex hormone-binding globulins in relation to lifestyle factors in older African-American, white, and Asian men in the United States and Canada. Cancer epidemiology, biomarkers \& prevention : a publication of the American Association for Cancer Research, cosponsored by the American Society of Preventive Oncology 1995; 4:735-41.

55. Winters SJ, Brufsky A, Weissfeld J, Trump DL, Dyky MA, Hadeed V. Testosterone, sex hormone-binding globulin, and body composition in young adult African American and Caucasian men. Metabolism: clinical and experimental 2001; 50:1242-7. 
56. Richard A, Rohrmann S, Zhang L, Eichholzer M, Basaria S, Selvin E, Dobs AS, Kanarek N, Menke A, Nelson WG, et al. Racial variation in sex steroid hormone concentration in black and white men: a meta-analysis. Andrology 2014; 2:428-35.

57. Watts EL, Appleby PN, Perez-Cornago A, Bueno-de-Mesquita HB, Chan JM, Chen C, Cohn BA, Cook MB, Flicker L, Freedman ND, et al. Low Free Testosterone and Prostate Cancer Risk: A Collaborative Analysis of 20 Prospective Studies. European urology 2018; 74:585-94.

58. Lopez DS, Peskoe SB, Joshu CE, Dobs A, Feinleib M, Kanarek N, Nelson WG, Selvin E, Rohrmann S, Platz EA. Racial/ethnic differences in serum sex steroid hormone concentrations in US adolescent males. Cancer causes \& control : CCC 2013; 24:81726.

59. Rohrmann S, Nelson WG, Rifai N, Brown TR, Dobs A, Kanarek N, Yager JD, Platz EA. Serum estrogen, but not testosterone, levels differ between black and white men in a nationally representative sample of Americans. The Journal of clinical endocrinology and metabolism 2007; 92:2519-25.

60. Abdelrahaman E, Raghavan S, Baker L, Weinrich M, Winters SJ. Racial difference in circulating sex hormone-binding globulin levels in prepubertal boys. Metabolism: clinical and experimental 2005; 54:91-6.

61. Joseph MA, Wei JT, Harlow SD, Cooney KA, Dunn RL, Jaffe CA, Montie JE, Schottenfeld D. Relationship of serum sex-steroid hormones and prostate volume in African American men. The Prostate 2002; 53:322-9. 
62. Yu J, Yu J, Mani RS, Cao Q, Brenner CJ, Cao X, Wang X, Wu L, Li J, Hu M, et al. An integrated network of androgen receptor, polycomb, and TMPRSS2-ERG gene fusions in prostate cancer progression. Cancer cell 2010; 17:443-54.

63. Lei Q, Jiao J, Xin L, Chang C-J, Wang S, Gao J, Gleave ME, Witte ON, Liu X, Wu H. NKX3.1 stabilizes p53, inhibits AKT activation, and blocks prostate cancer initiation caused by PTEN loss. Cancer cell 2006; 9:367-78.

64. Sharma Naomi L, Massie Charlie E, Ramos-Montoya A, Zecchini V, Scott Helen E, Lamb Alastair D, MacArthur S, Stark R, Warren Anne Y, Mills lan G, et al. The Androgen Receptor Induces a Distinct Transcriptional Program in Castration-Resistant Prostate Cancer in Man. Cancer cell 2013; 23:35-47.

65. Liu S, Kumari S, Hu Q, Senapati D, Venkadakrishnan VB, Wang D, DePriest AD, Schlanger SE, Ben-Salem S, Valenzuela MM, et al. A comprehensive analysis of coregulator recruitment, androgen receptor function and gene expression in prostate cancer. elife 2017; 6.

66. Asbell SO, Raimane KC, Montesano AT, Zeitzer KL, Asbell MD, Vijayakumar S. Prostate-specific antigen and androgens in African-American and white normal subjects and prostate cancer patients. J Natl Med Assoc 2000; 92:445-9.

67. Osegbe DN, Ogunlewe JO. Androgen concentration in blacks with benign and malignant prostatic disease. J Urol 1988; 140:160-4.

68. Härkönen Pi, Törn S, Kurkela R, Porvari K, Pulkka A, Lindfors A, Isomaa V, Vihko P. Sex Hormone Metabolism in Prostate Cancer Cells during Transition to an AndrogenIndependent State. The Journal of Clinical Endocrinology \& Metabolism 2003; 88:705-12. 
69. Hammond GL. Plasma steroid-binding proteins: primary gatekeepers of steroid hormone action. J Endocrinol 2016; 230:R13-R25.

70. Liu PY, Beilin J, Meier C, Nguyen TV, Center JR, Leedman PJ, Seibel MJ, Eisman JA, Handelsman DJ. Age-Related Changes in Serum Testosterone and Sex Hormone Binding Globulin in Australian Men: Longitudinal Analyses of Two Geographically Separate Regional Cohorts. The Journal of Clinical Endocrinology \& Metabolism 2007; 92:3599-603.

71. $\mathrm{Xu} \mathrm{X}$, Chen X, Hu H, Dailey AB, Taylor BD. Current opinion on the role of testosterone in the development of prostate cancer: a dynamic model. BMC cancer 2015; 15:806.

72. Wang K, Chen X, Bird VY, Gerke TA, Manini TM, Prosperi M. Association between age-related reductions in testosterone and risk of prostate cancer-An analysis of patients' data with prostatic diseases. International journal of cancer $2017 ; 141: 1783-93$.

73. Michaud JE, Billups KL, Partin AW. Testosterone and prostate cancer: an evidence-based review of pathogenesis and oncologic risk. Ther Adv Urol 2015; 7:37887.

74. Dunn JF, Nisula BC, Rodbard D. Transport of steroid hormones: binding of 21 endogenous steroids to both testosterone-binding globulin and corticosteroid-binding globulin in human plasma. The Journal of clinical endocrinology and metabolism 1981; 53:58-68.

75. Kaipainen A, Zhang A, Gil da Costa RM, Lucas J, Marck B, Matsumoto AM, Morrissey C, True LD, Mostaghel EA, Nelson PS. Testosterone accumulation in prostate cancer cells is enhanced by facilitated diffusion. The Prostate 2019; 79:1530-42. 
76. Grino PB, Griffin JE, Wilson JD. Testosterone at high concentrations interacts with the human androgen receptor similarly to dihydrotestosterone. Endocrinology 1990; 126:1165-72.

77. Pereira de Jésus-Tran K, Côté P-L, Cantin L, Blanchet J, Labrie F, Breton R. Comparison of crystal structures of human androgen receptor ligand-binding domain complexed with various agonists reveals molecular determinants responsible for binding affinity. Protein Sci 2006; 15:987-99.

78. Deslypere JP, Young M, Wilson JD, McPhaul MJ. Testosterone and 5 alphadihydrotestosterone interact differently with the androgen receptor to enhance transcription of the MMTV-CAT reporter gene. Molecular and cellular endocrinology 1992; 88:15-22.

79. Gao W, Bohl CE, Dalton JT. Chemistry and structural biology of androgen receptor. Chemical reviews 2005; 105:3352-70.

80. Penning TM. Molecular Endocrinology of Hydroxysteroid Dehydrogenases*. Endocrine Reviews 1997; 18:281-305.

81. Mohler JL, Titus MA, Bai S, Kennerley BJ, Lih FB, Tomer KB, Wilson EM. Activation of the androgen receptor by intratumoral bioconversion of androstanediol to dihydrotestosterone in prostate cancer. Cancer research 2011; 71:1486-96.

82. Magi-Galluzzi C, Maddala T, Falzarano SM, Cherbavaz DB, Zhang N, Knezevic D, Febbo PG, Lee M, Lawrence HJ, Klein EA. Gene expression in normal-appearing tissue adjacent to prostate cancers are predictive of clinical outcome: evidence for a biologically meaningful field effect. Oncotarget 2016; 7:33855-65. 
83. Nonn L, Ananthanarayanan V, Gann PH. Evidence for field cancerization of the prostate. The Prostate 2009; 69:1470-9.

84. Niu Y, Altuwaijri S, Lai KP, Wu CT, Ricke WA, Messing EM, Yao J, Yeh S, Chang C. Androgen receptor is a tumor suppressor and proliferator in prostate cancer. Proceedings of the National Academy of Sciences of the United States of America 2008; 105:12182-7.

85. Tanner MJ, Welliver RC, Jr., Chen M, Shtutman M, Godoy A, Smith G, Mian BM, Buttyan R. Effects of Androgen Receptor and Androgen on Gene Expression in Prostate Stromal Fibroblasts and Paracrine Signaling to Prostate Cancer Cells. PloS one 2011; 6:e16027.

\section{6. https://respondstudy.org/.}

87. https://www.pcf.org/sprt/.

88. Awasthi S, Berglund A, Abraham-Miranda J, Rounbehler RJ, Kensler K, Serna A, Vidal A, You S, Freeman MR, Davicioni E, et al. Comparative Genomics Reveals Distinct Immune-oncologic Pathways in African American Men with Prostate Cancer. Clinical Cancer Research 2020.

89. Koga Y, Song H, Chalmers ZR, Newberg J, Kim E, Carrot-Zhang J, Piou D, Polak P, Abdulkadir SA, Ziv E, et al. Genomic Profiling of Prostate Cancers from Men with African and European Ancestry. Clinical Cancer Research 2020; 26:4651-60.

90. Yuan J, Kensler KH, Hu Z, Zhang Y, Zhang T, Jiang J, Xu M, Pan Y, Long M, Montone KT, et al. Integrative comparison of the genomic and transcriptomic landscape between prostate cancer patients of predominantly African or European genetic ancestry. PLoS genetics 2020; 16:e1008641. 
91. Croghan C, Egeghy PP. Methods of dealing with values below the limit of detection using SAS. Southern SAS User Group 2003; 22:24.

92. Teteh DK, Dawkins-Moultin L, Hooker S, Hernandez W, Bonilla C, Galloway D, LaGroon V, Santos ER, Shriver M, Royal CDM, et al. Genetic ancestry, skin color and social attainment: The four cities study. PloS one 2020; 15:e0237041. 


\section{Figure legends}

Figure 1 Enzymes involved in DHT biosynthesis from alternate pathways are overexpressed in PrCa from AA men. A. Pie charts represent the distribution of the type of gene categories that are differentially expressed in $\mathrm{PrCa}$ tissues from AA men compared to EA men from Roswell Park Cohort 1. The left pie chart represents the top 500 downregulated genes in PrCa tissues from AA men. The right pie chart represents the top 500 upregulated genes in PrCa tissues from AA men. B. The heatmap represents a subset of enzymes involved in alternate pathways of androgen biosynthesis that are differentially expressed in $\mathrm{PrCa}$ and adjacent non-tumor tissues from $\mathrm{AA}$ and $\mathrm{EA}$ men in Roswell Park Cohort 1.

Figure 2 Enzymes involved in DHT synthesis from alternate pathways are significantly dysregulated in PrCa and adjacent non-tumor tissues from AA and EA men. A. The heatmap represents the computed $p$-values obtained upon race and tissue comparisons of enzymes involved in alternate pathways of androgen synthesis. Twogroup test $p$-values within factors were performed for race comparisons. Within race, paired sample t-test is performed, accounting for the paired structure of the data. Each column represents comparisons between tumor and adjacent non-tumor tissues or tissuespecific comparisons between AA and EA men. Dark blue rectangles represent those comparisons that are significantly different in each comparison. B and C. qPCR validation of RNA-sequencing results show differential expression of AKR1C1 and AKR1C2 in a subset of PrCa and adjacent non-tumor tissues from AA and EA men.

Figure 3 Distribution of T and DHT in the serum of AA and EA men with PrCa. A. LC-MS/MS analysis of androgens reveals that the distribution of T levels are significantly 
different in the serum of AA men compared to EA men with $\operatorname{PrCa}(p<0.05)$. B. The distribution of DHT in the serum are comparable between AA men and EA men with PrCa. Blue lines represent the frequency of distribution of $T$ and DHT levels in the serum of AA men with PrCa, and pink lines represent the frequency of distribution of $\mathrm{T}$ and $\mathrm{DHT}$ levels in the serum of EA men with PrCa.

Figure 4 Expression of enzymes involved in DHT biosynthesis from alternate pathways are correlated to DHT levels in the serum of AA men with PrCa. GSVA scores were calculated for the following enzymes: AKR1C3, DHRS9, HSD17B3, HSD3B1, HSD3B2, RDH5, SRD5A1, SRD5A2, and CYP19A1. Pearson correlation analysis were calculated for GSVA scores and DHT levels in the serum. The first column displays correlation with expression in PrCa tissues ( $T$ ). The second column displays correlation with expression in adjacent non-tumor tissues (NT). The third column displays correlation with normalized expression in tumor tissues (T/NT). The X-axis represents the GSVA score, and the $\mathrm{Y}$-axis represents the bin centers from frequency distribution analysis of DHT levels in the serum $(\mathrm{ng} / \mathrm{mL})$. A. Represents clinical samples from AA men with PrCa B. Represents clinical samples from EA men with PrCa.

Figure 5 Serum distribution of intermediate metabolites produced during alternate DHT biosynthesis pathways in AA and EA men with PrCa. LC-MS/MS analysis reveals that the frequency of high and low intermediate androgen metabolites levels in the serum are significantly different between AA men and EA men with PrCa.

Figure 6 Subset of intermediate metabolites in androgen synthesis measured in the serum are associated with AIMs. A. Spearman correlation analysis reveals that a subset of intermediate metabolites is correlated to AIMs. Blue represents positive 
correlation, and red represents negative correlation. *indicates significant correlation with p-value less than 0.05. B and C. The figures represent the SNPs identified in CYP11B1 and CYP11B2 in AA and EA men with PrCa. The SNPs labeled in orange represent those SNPs found at significantly higher frequencies in AA men with PrCa.

Figure 7 A subset of intermediate metabolites produced during DHT biosynthesis reflects shorter time to disease progression. Lower levels of intermediate androgen metabolites are associated with shorter time to disease progression in Roswell Park Cohort 2.

Figure 8 AR transcriptional activity is positively correlated to DHT levels in the serum of AA men with PrCa. GSVA scores were calculated for AR transcriptional targets: KLK2, KLK3, TMPRSS2 and NKX3.1, followed by correlation analysis with androgen levels in the serum. The first column displays correlation with expression in PrCa tissues $(\mathrm{T})$. The second column displays correlation with expression in adjacent non-tumor tissues (NT). The third column displays correlation with normalized expression in tumor tissues (T/NT). The X-axis represents the GSVA score, and the $\mathrm{Y}$-axis represents the level of androgens in the serum $(\mathrm{ng} / \mathrm{mL})$. The top panel is the correlation between DHT and AR activity, and the bottom panels represent the correlation between T and AR activity. A. Represents clinical samples from AA men with PrCa B. Represents clinical samples from EA men with PrCa.

Table 1 Androgen metabolites measured in the serum of AA and EA men with PrCa

Table 2 AR protein expression correlates to clinicopathological parameters 


\section{Metabolites in serum for circulation}

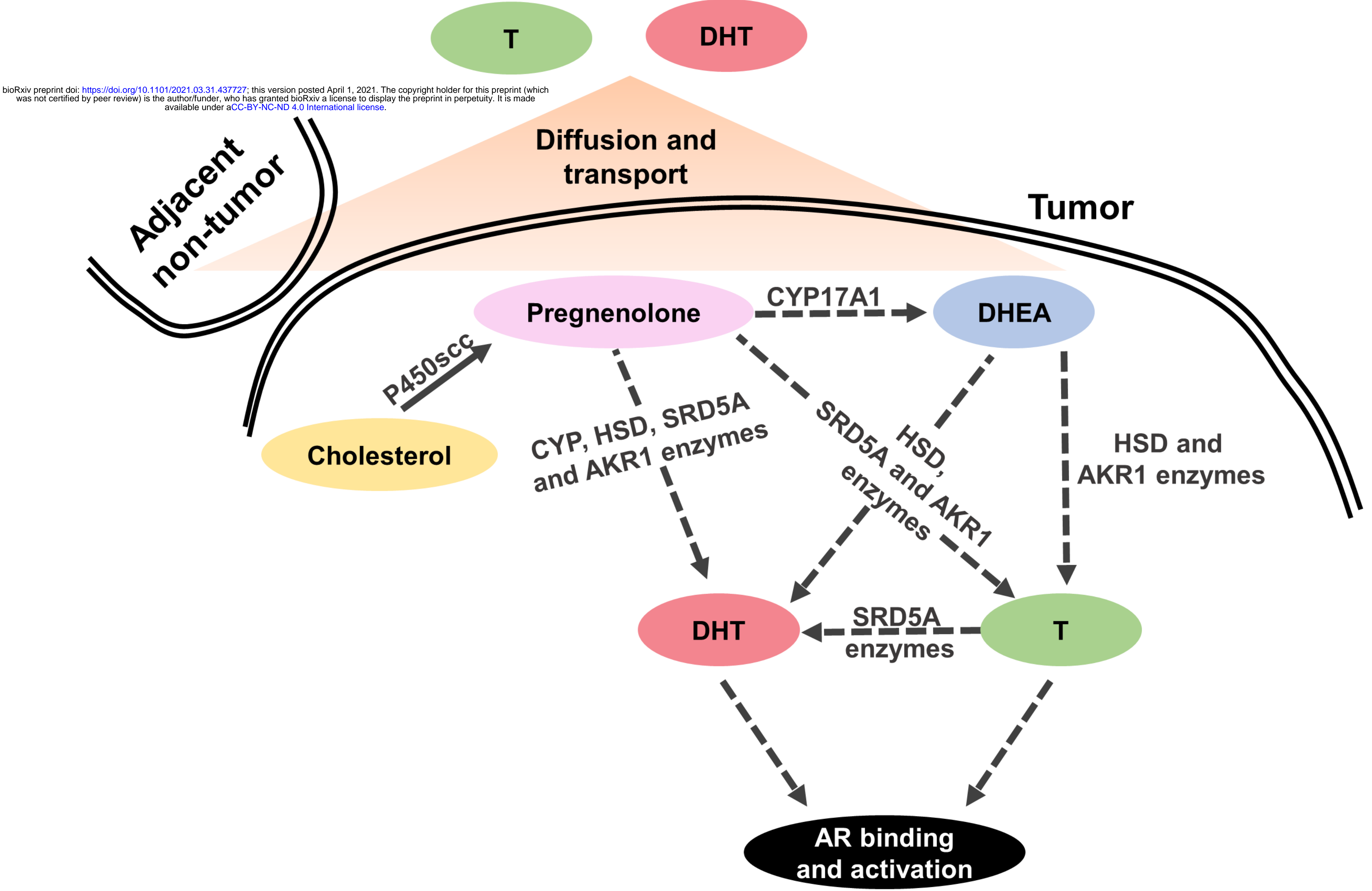



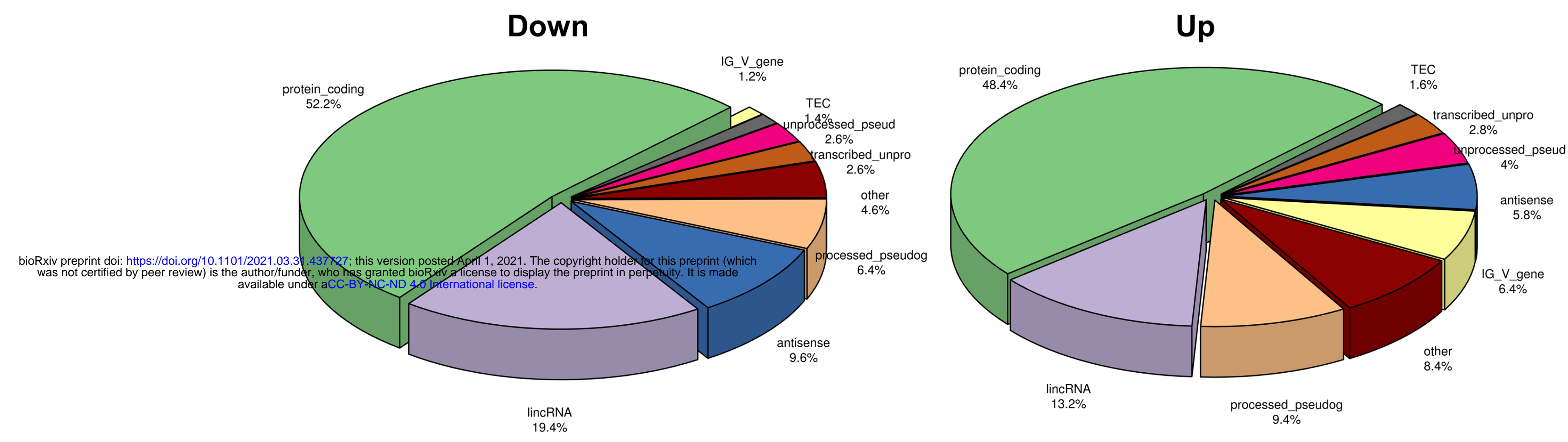

protein_coding lincRNA processed_pseudog IG_V_gene antisense unprocessed_pseud transcribed_unpro TEC other

B

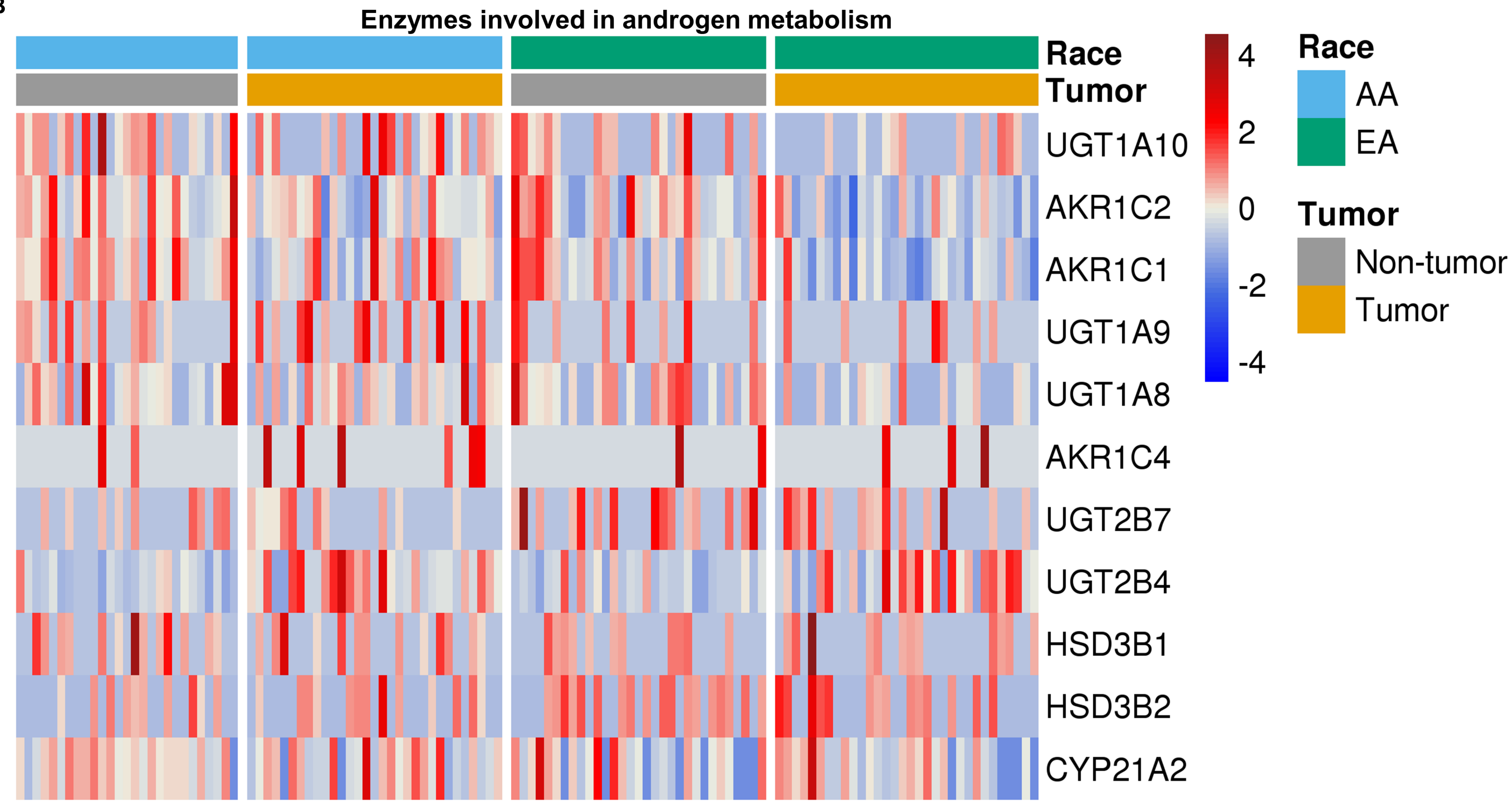


A

Androgen Metabolism Genes

Race and Tumor differences

Pvalues

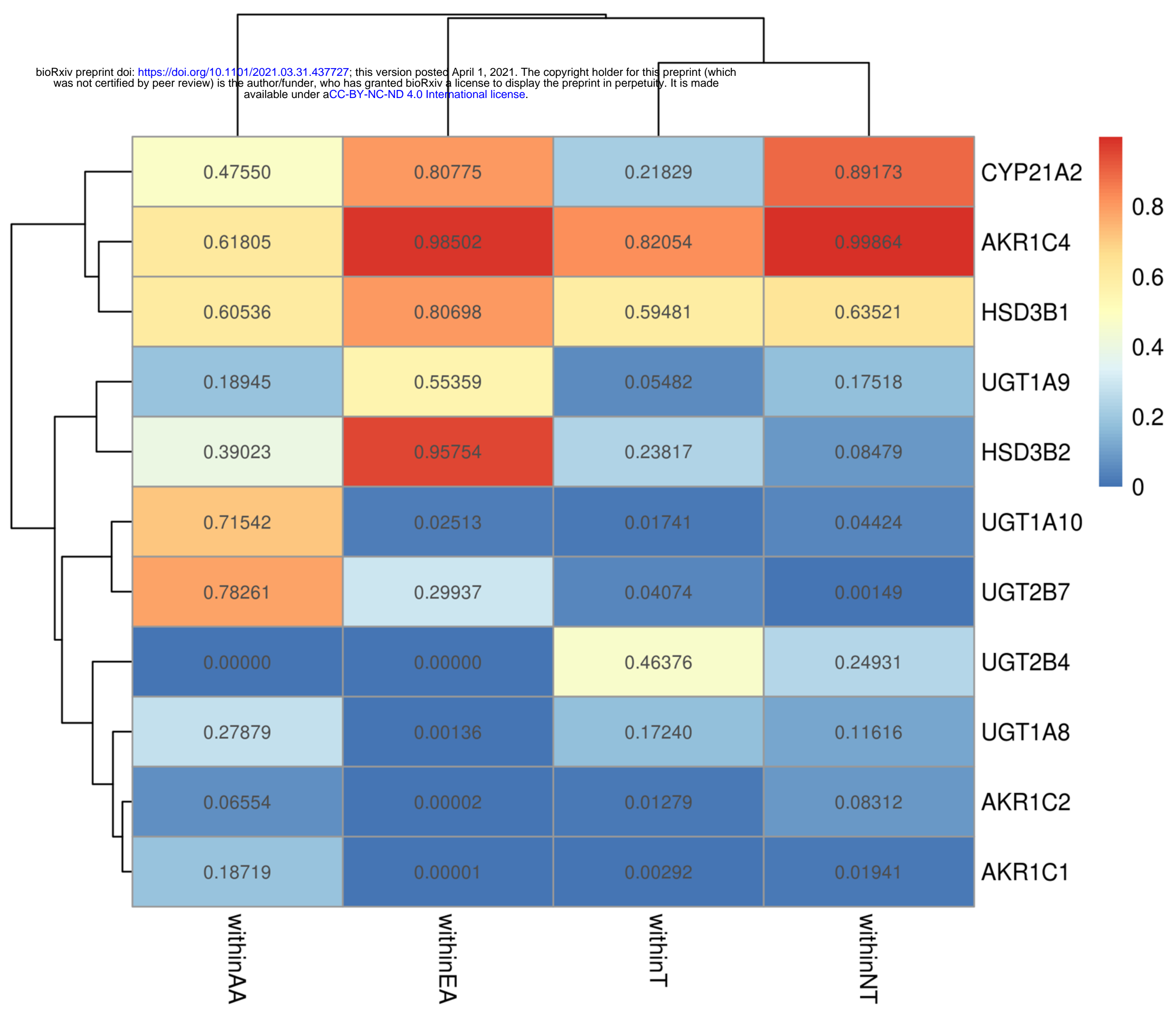

B

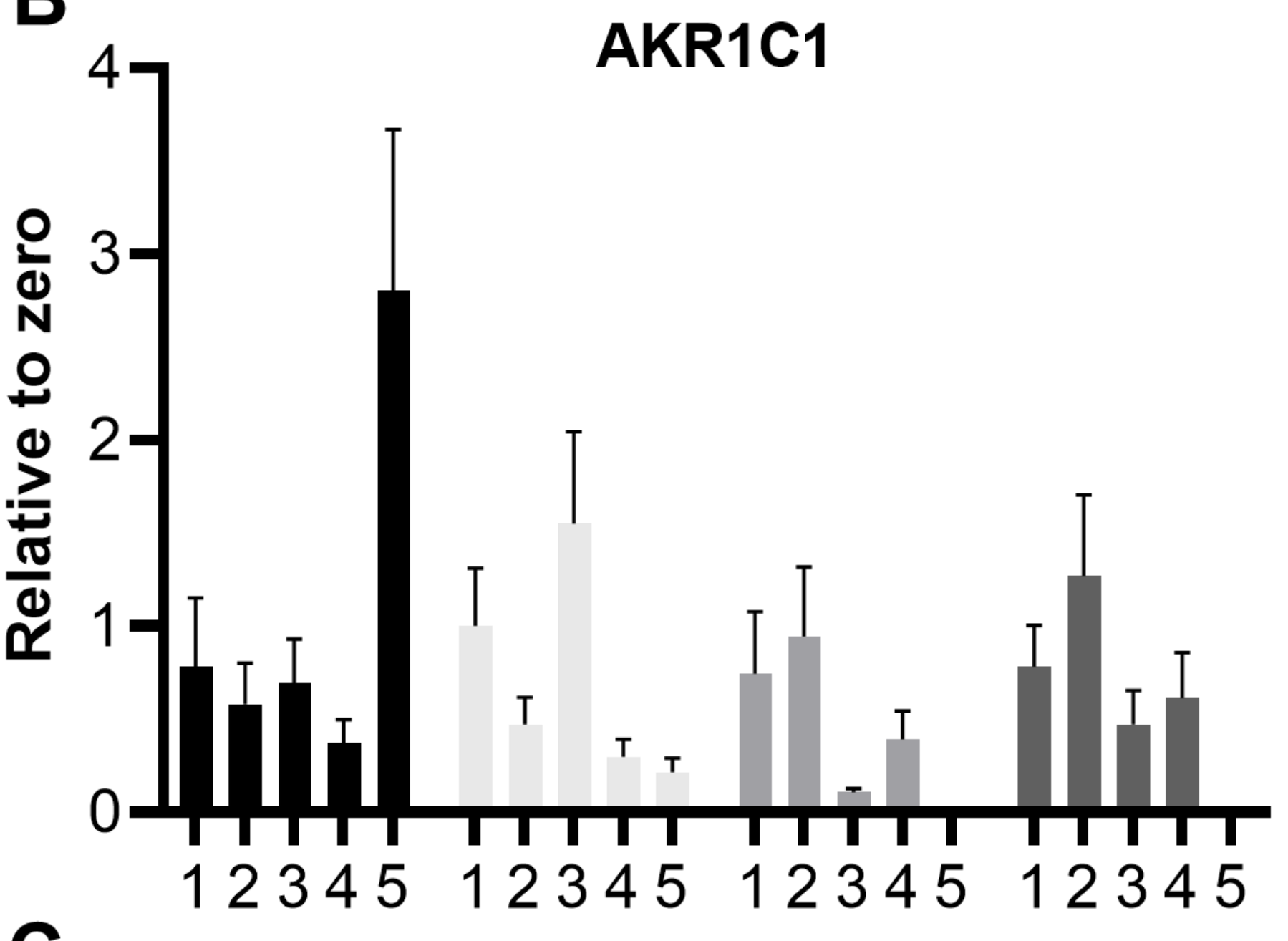

C

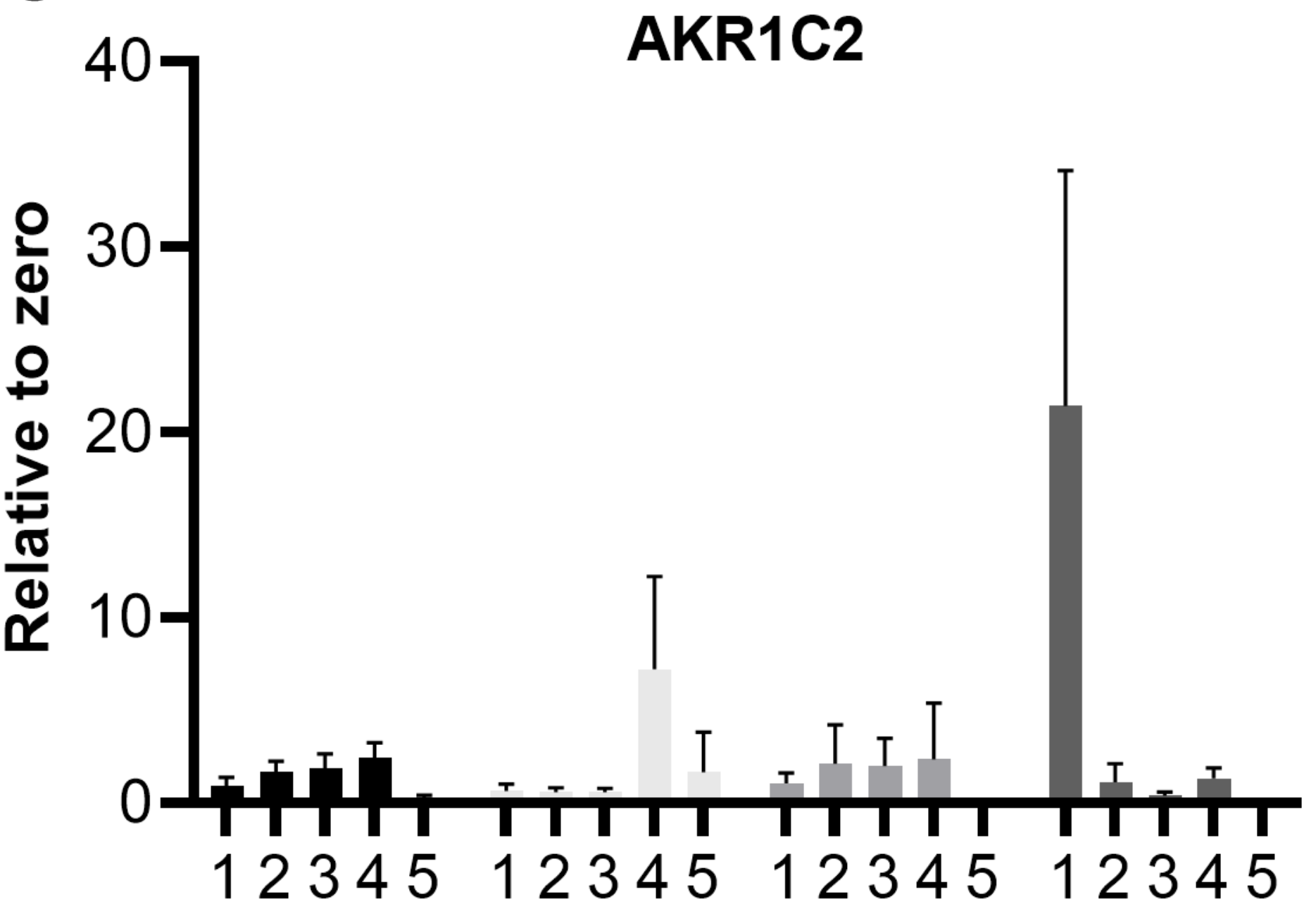

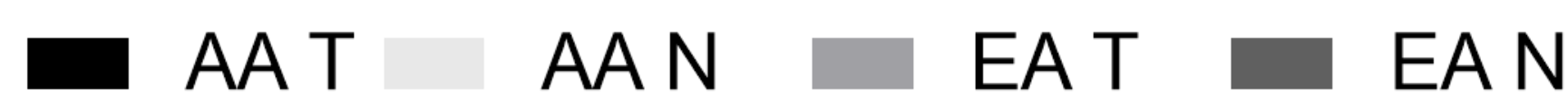


Figure 3

A

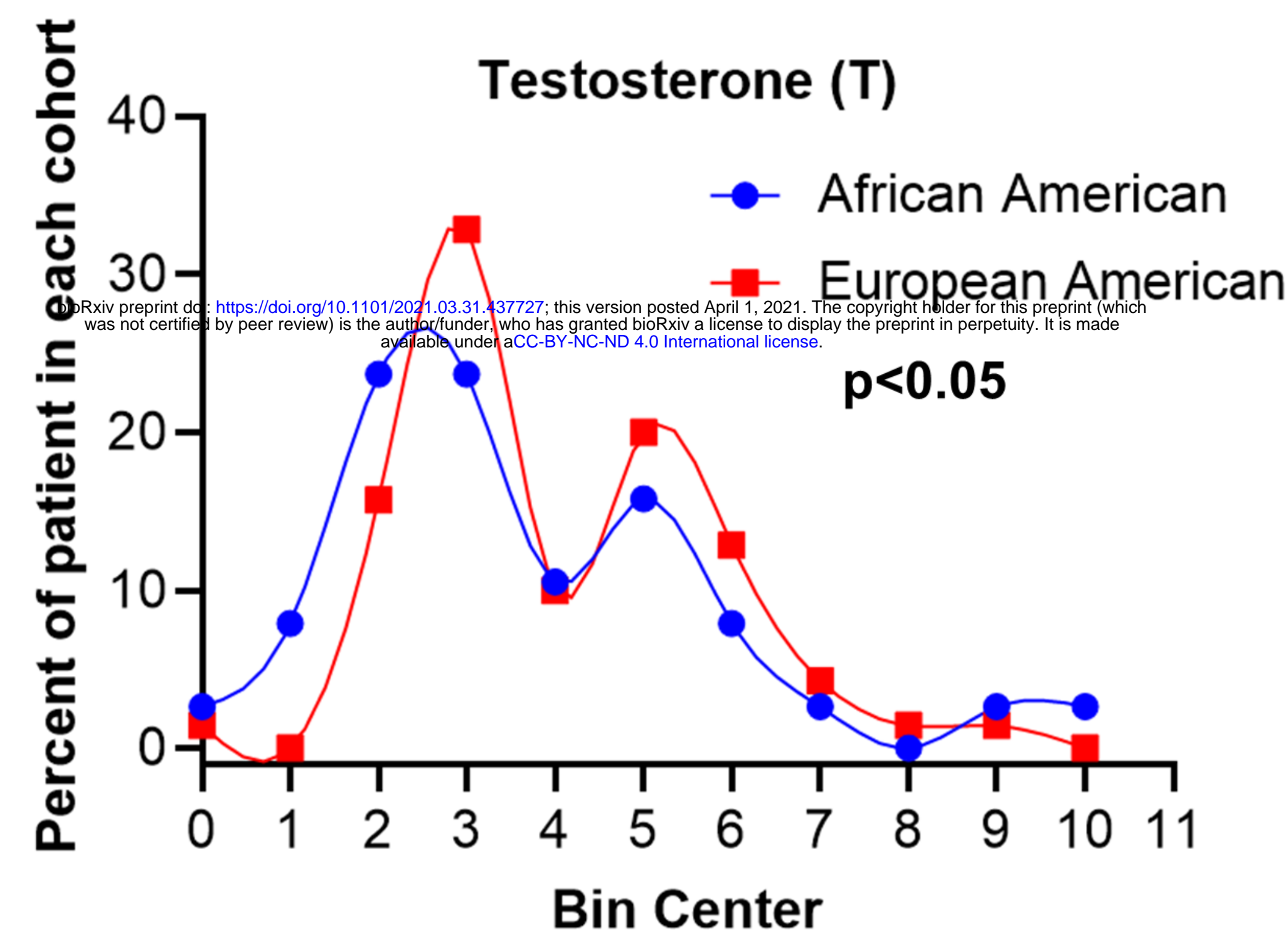

B

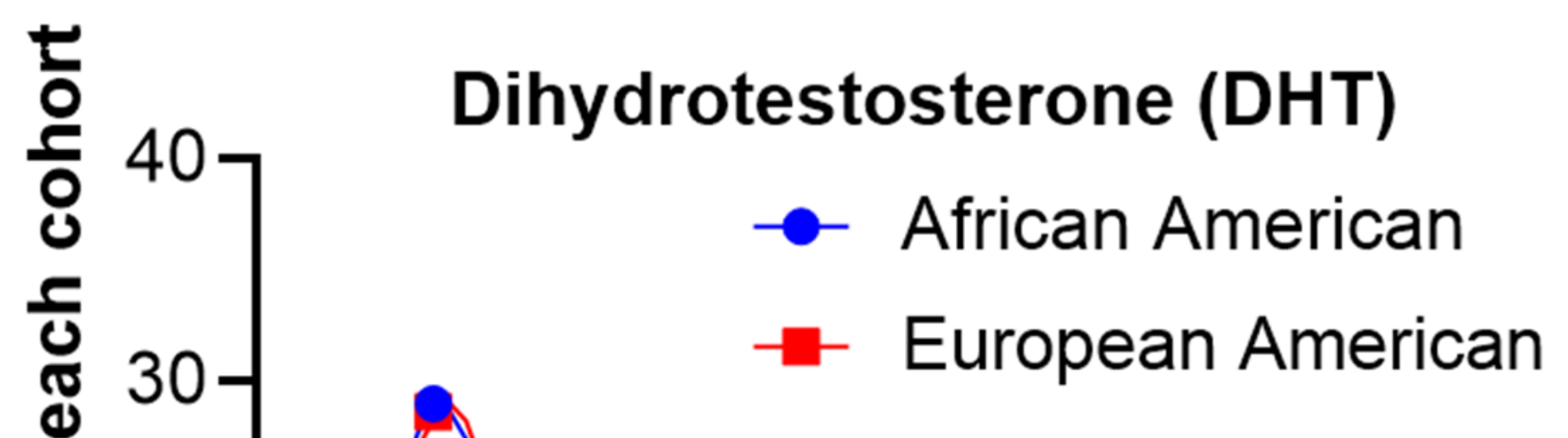
$p=0.334$

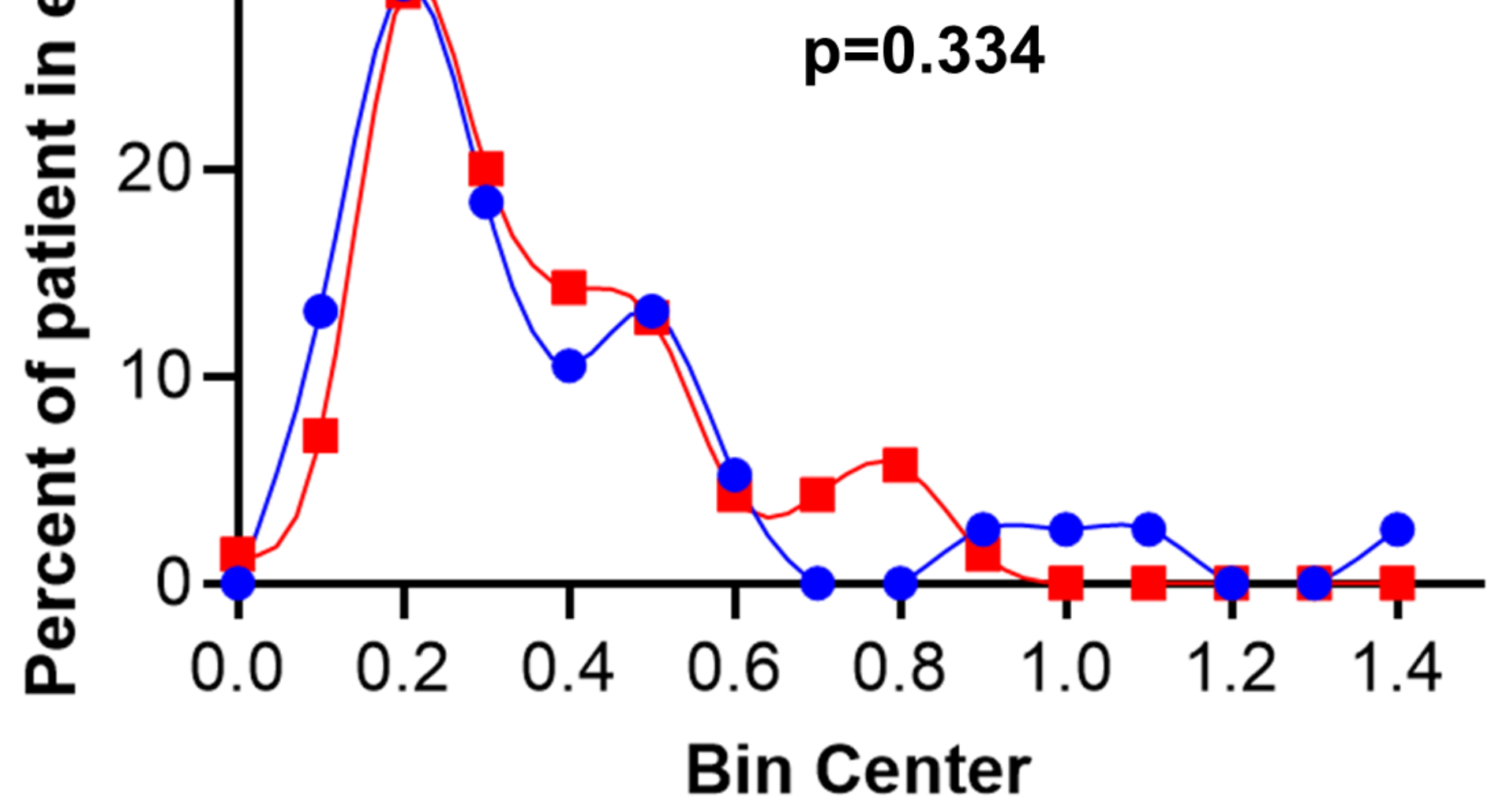


African American Samples

\section{Enrichment Scores Metabolite Level}

GSVA_T

$0.8-$

Cor (pearson): -0.43, pval: 0.29

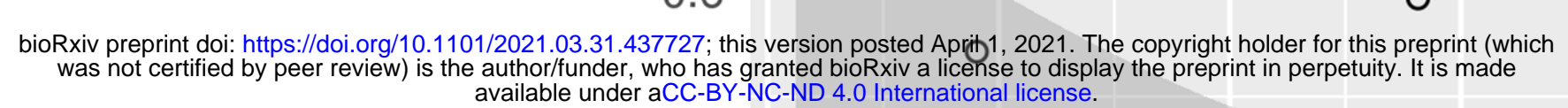

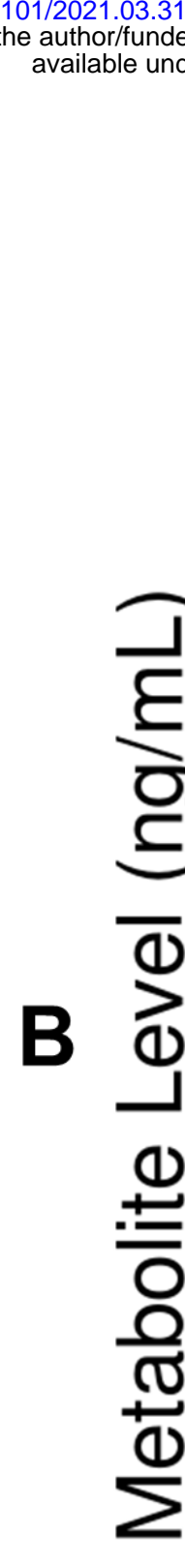

$0.4-$

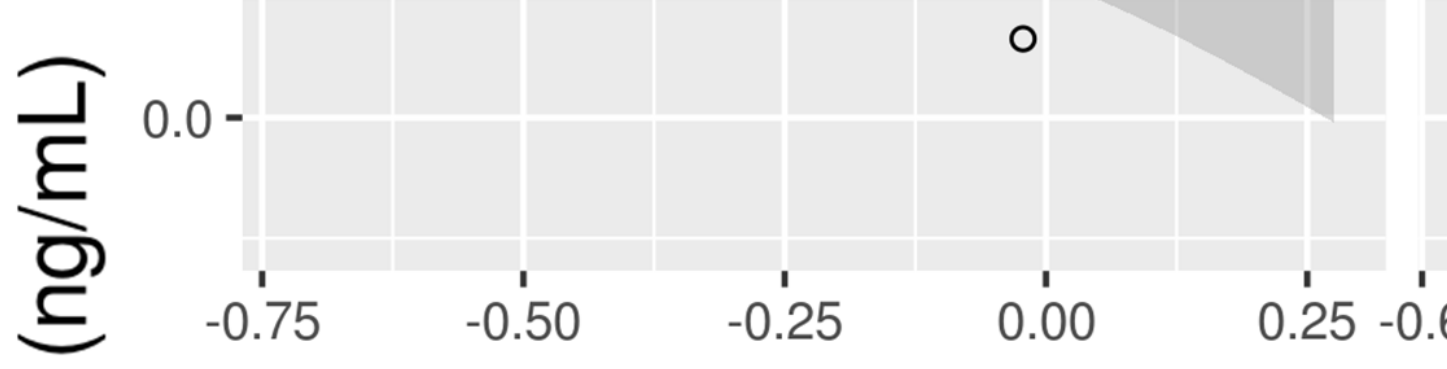

B

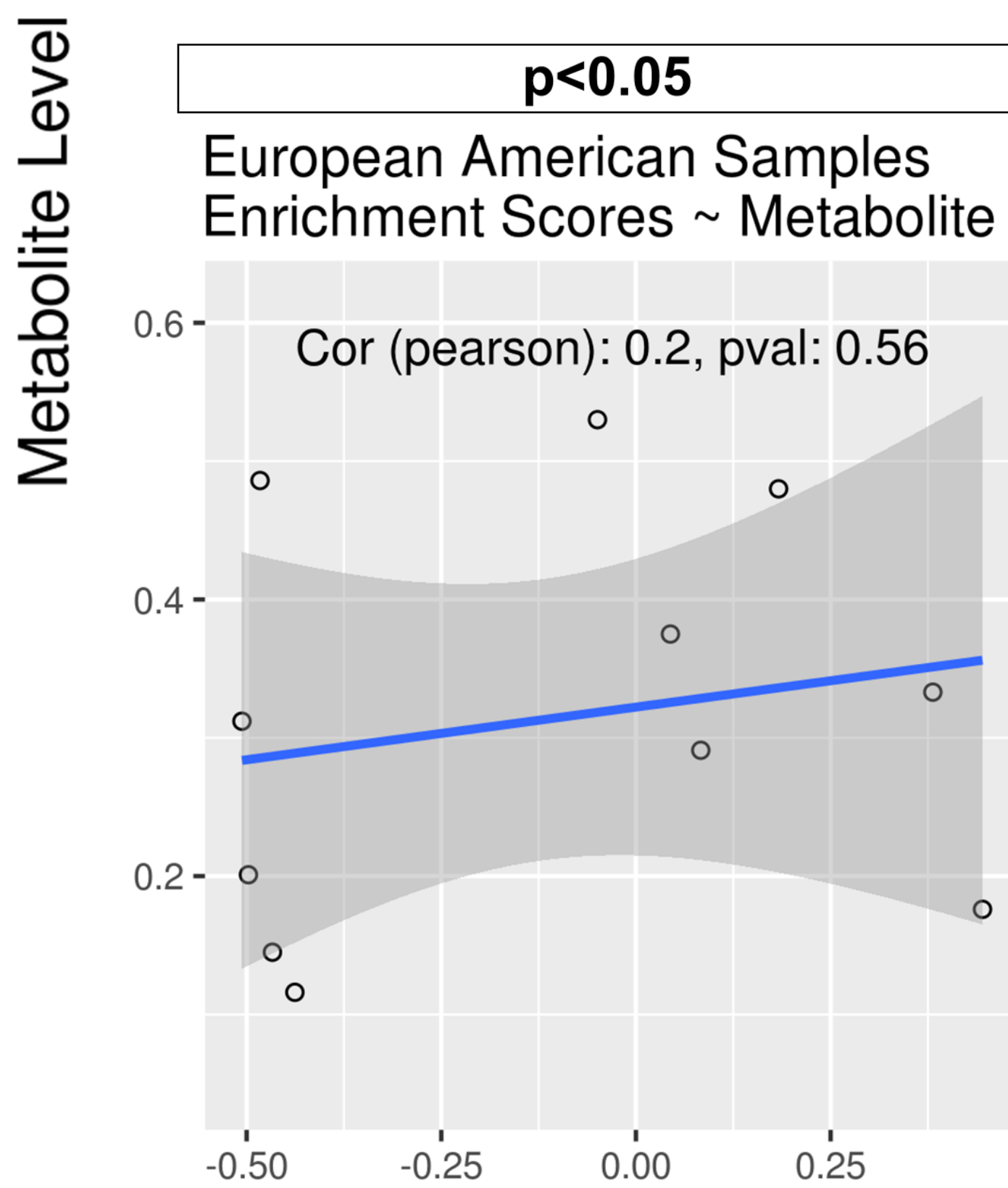

GSVA_NT
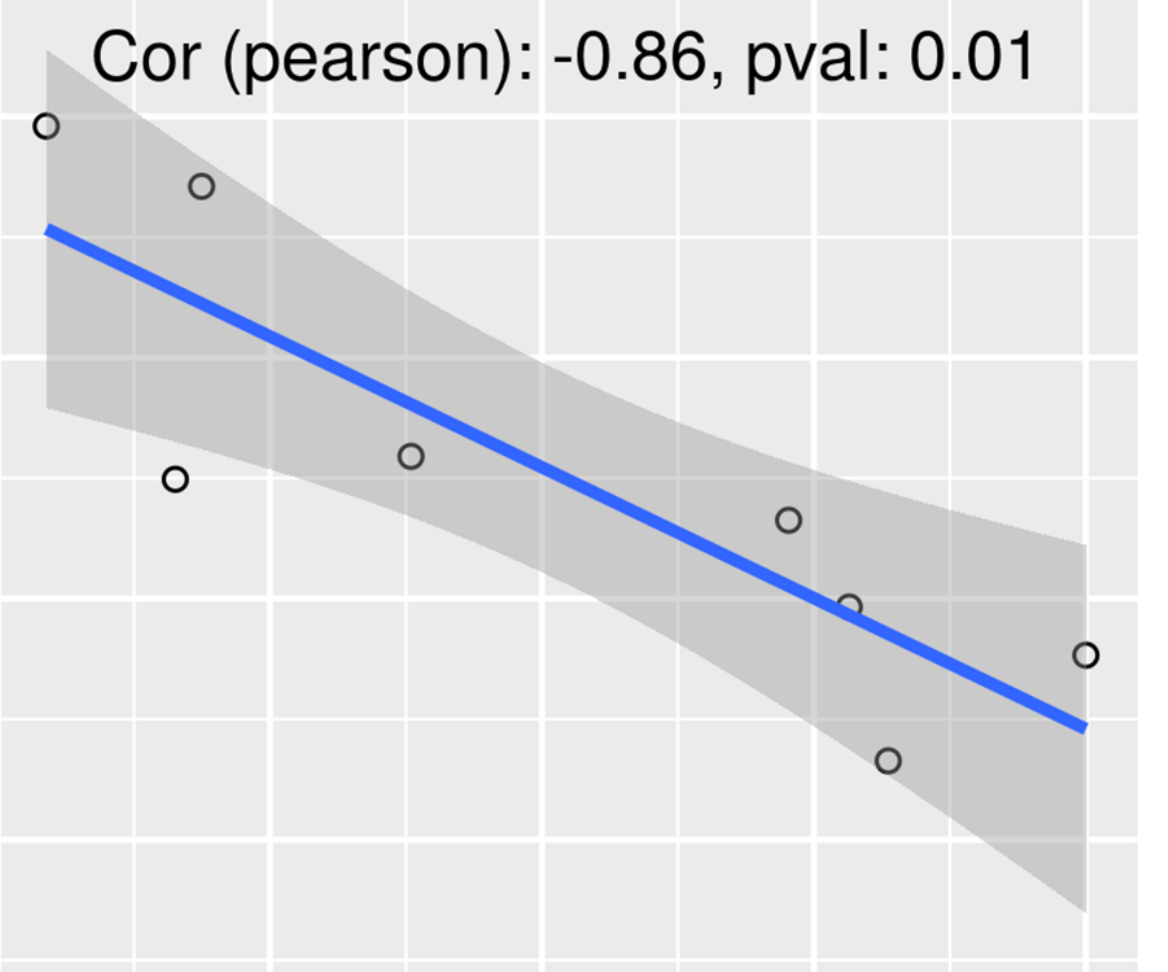

$$
p<0.01
$$

diff_GSVA
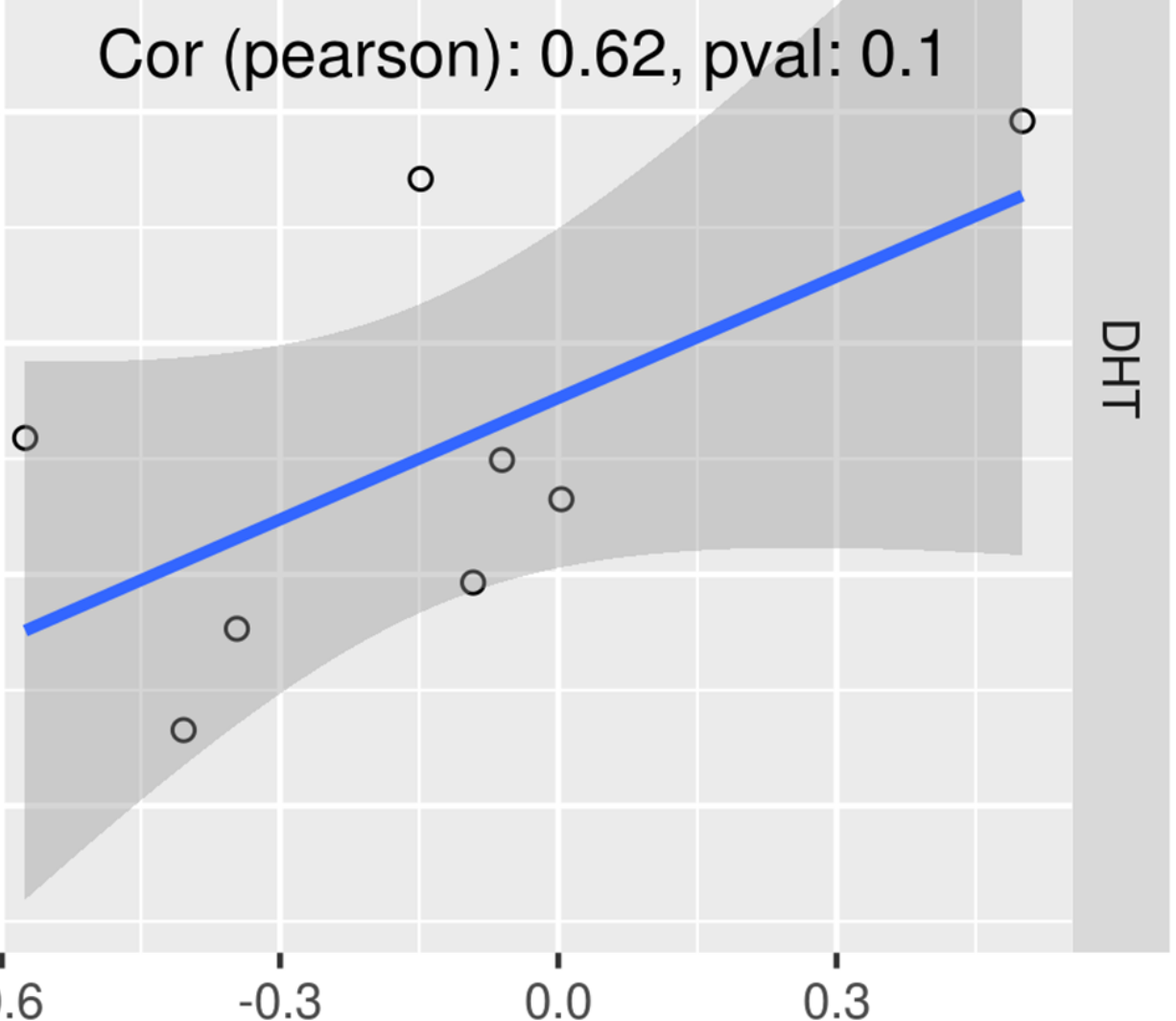

$p=0.079$

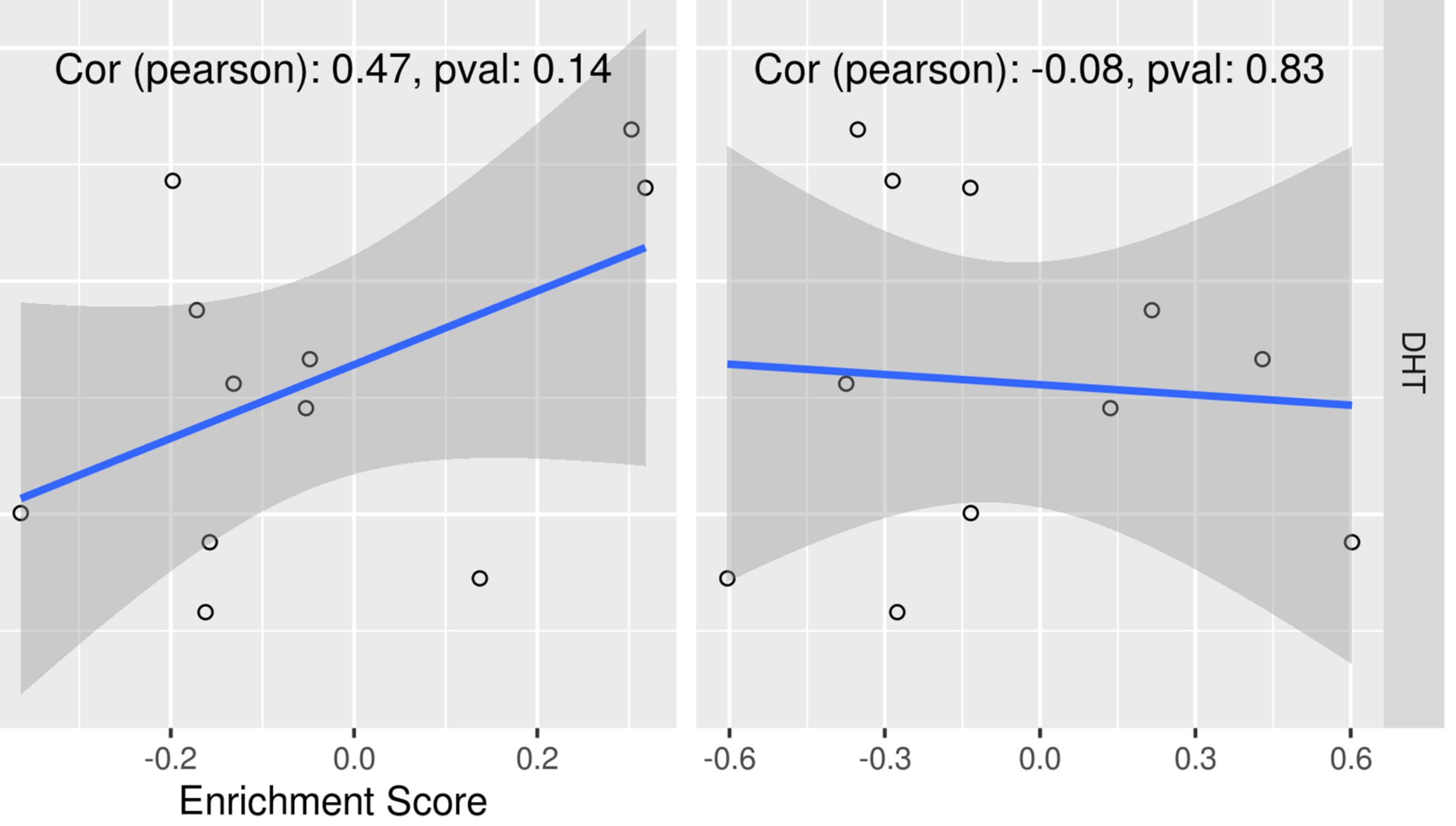


Figure 6

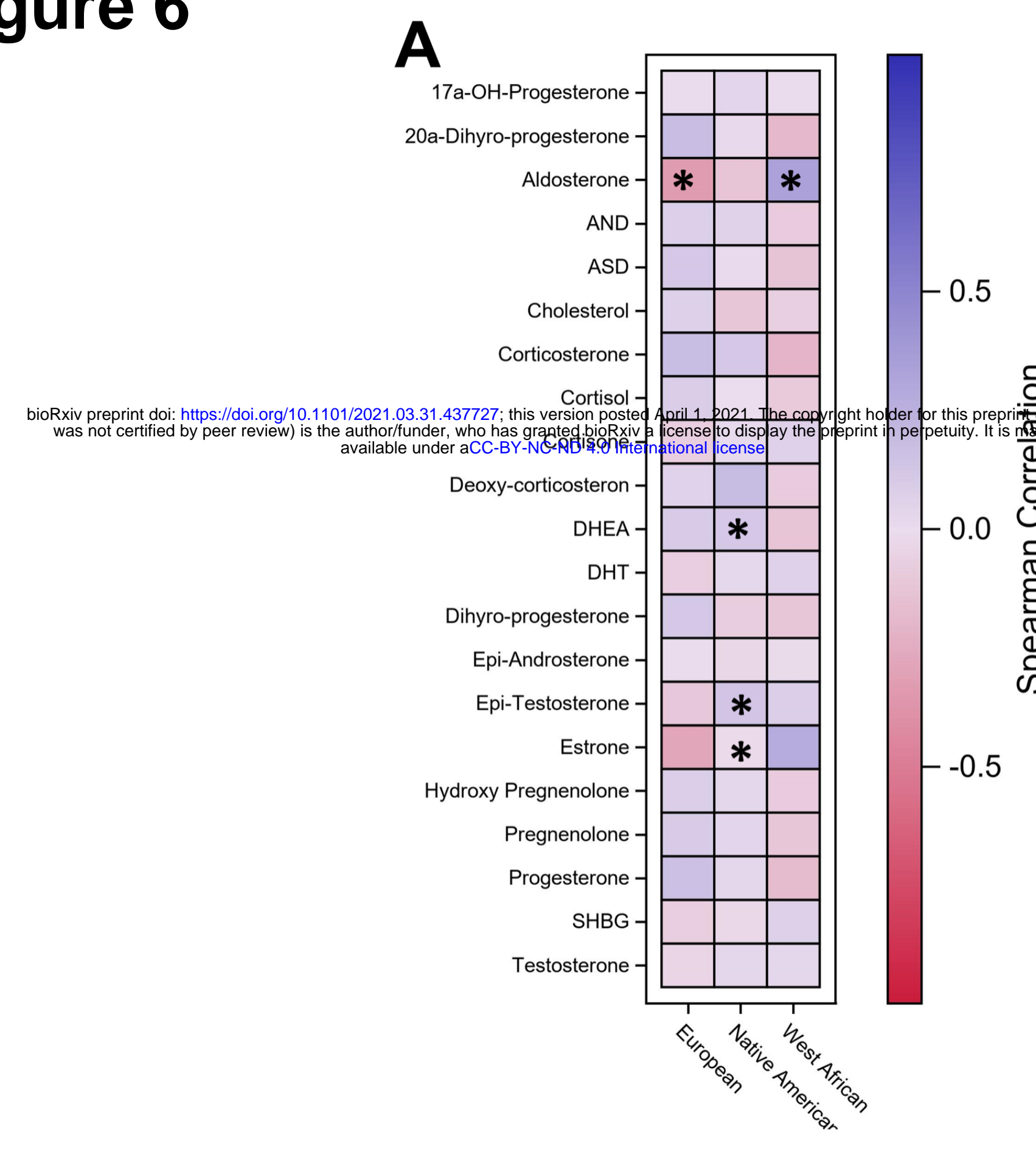

C

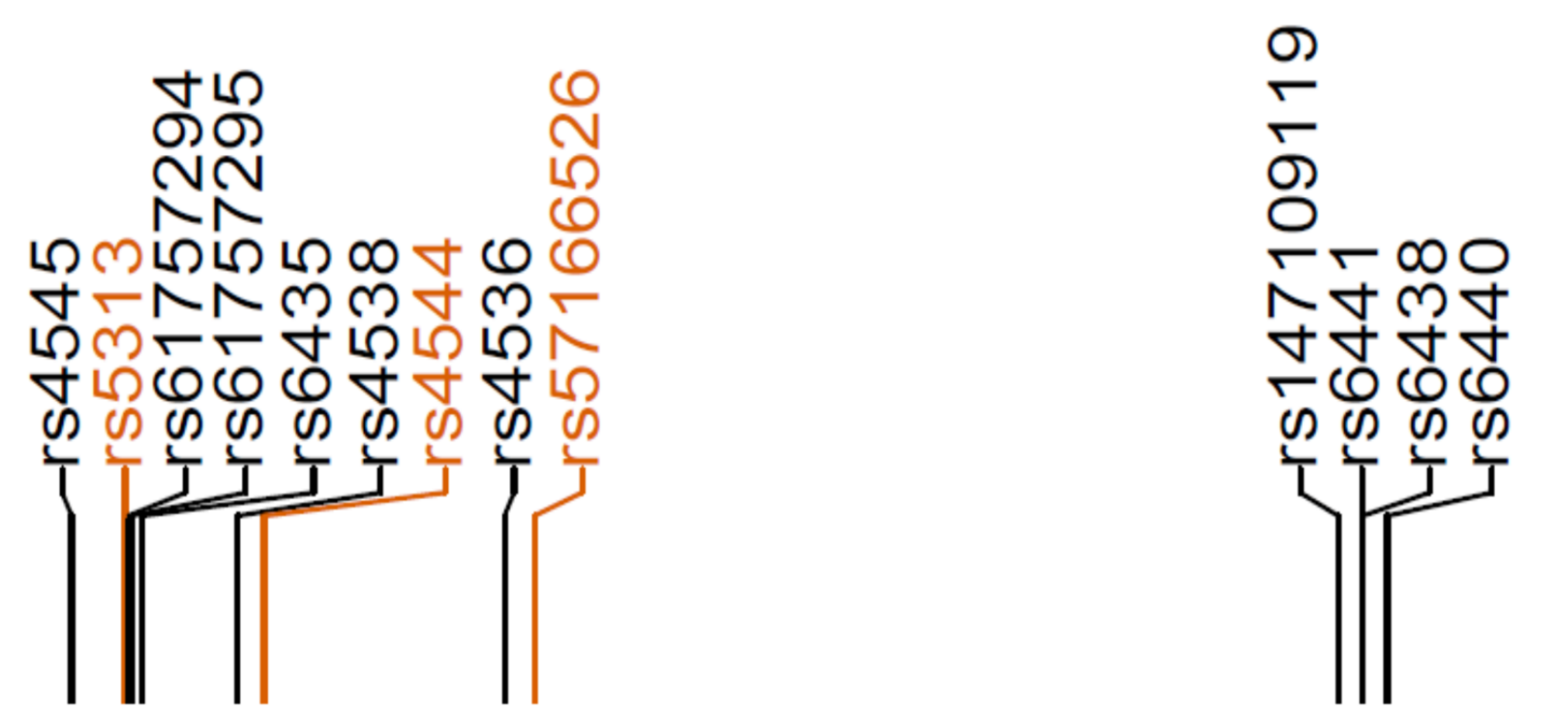

B

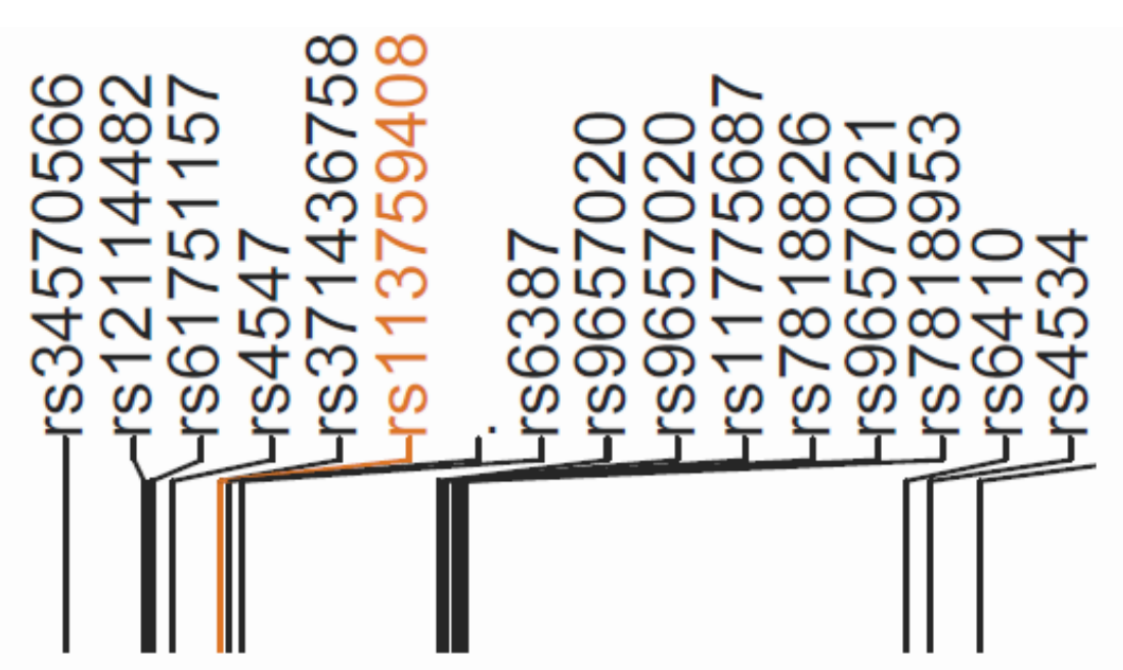

chr8

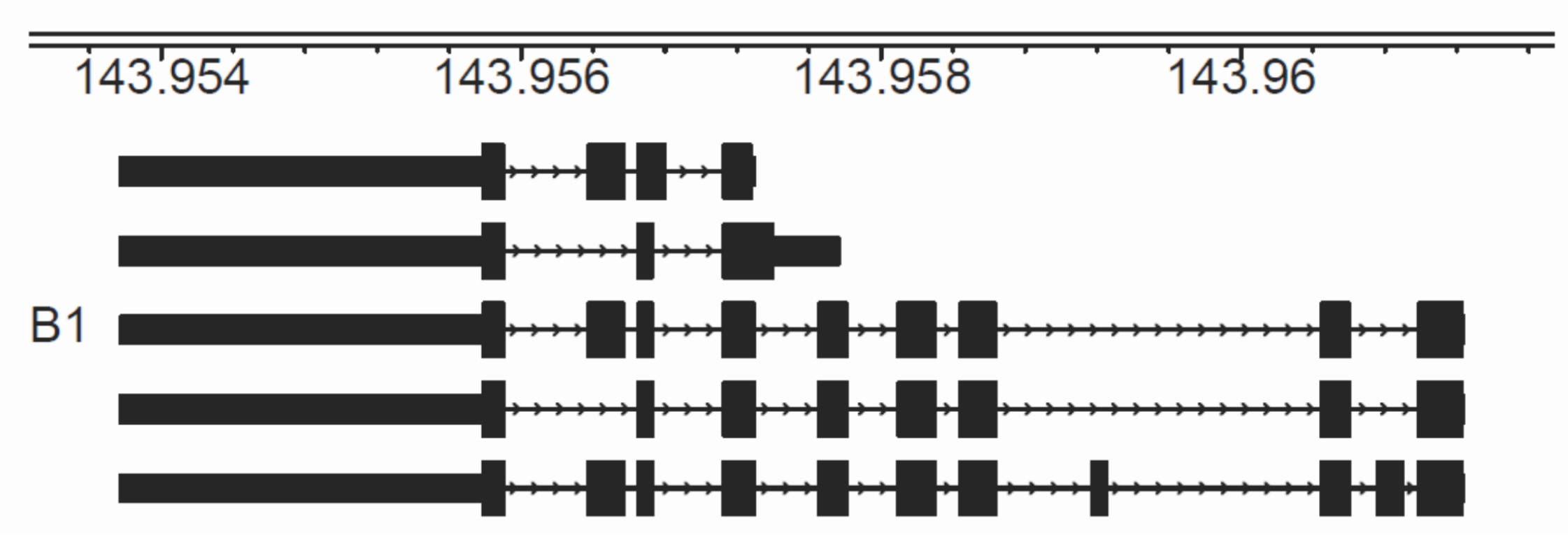

$1+4$

000

chr8

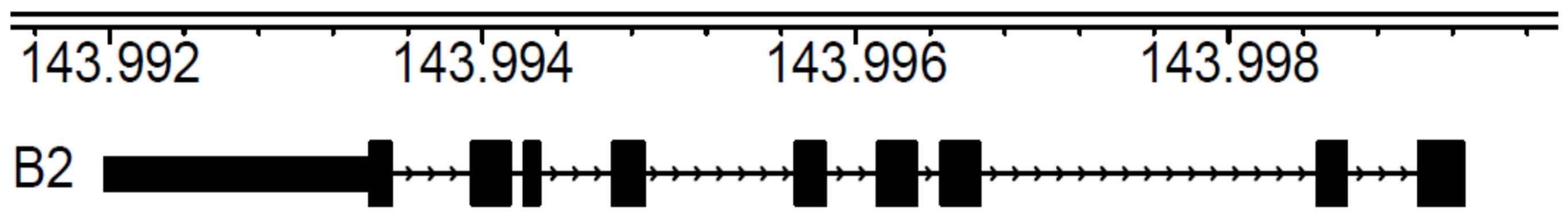


Figure 7

17- $\alpha-\mathrm{OH}-\mathrm{Progesterone}$

Freedom from RP Failure

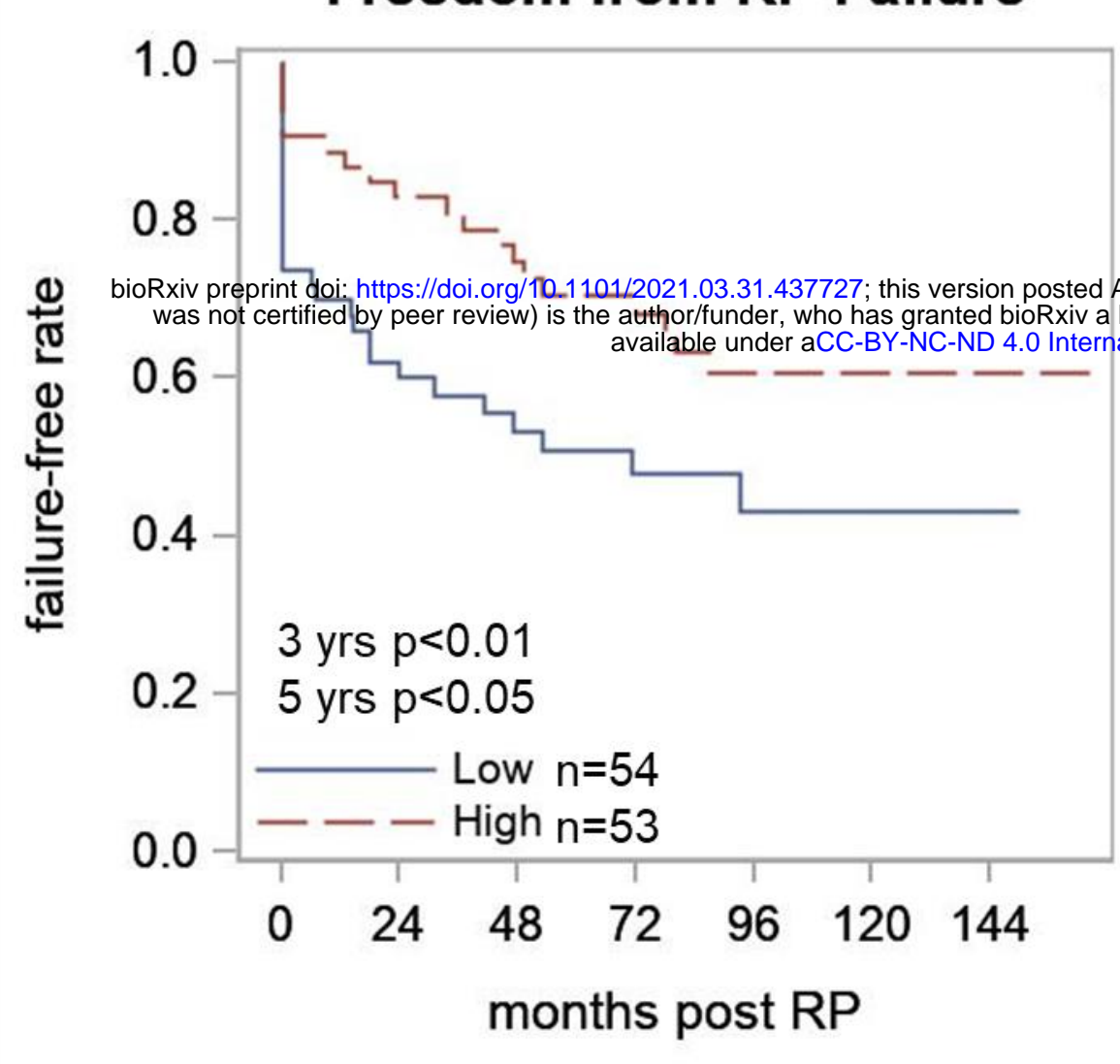

Non-esterified cholesterol

Freedom from RP Failure

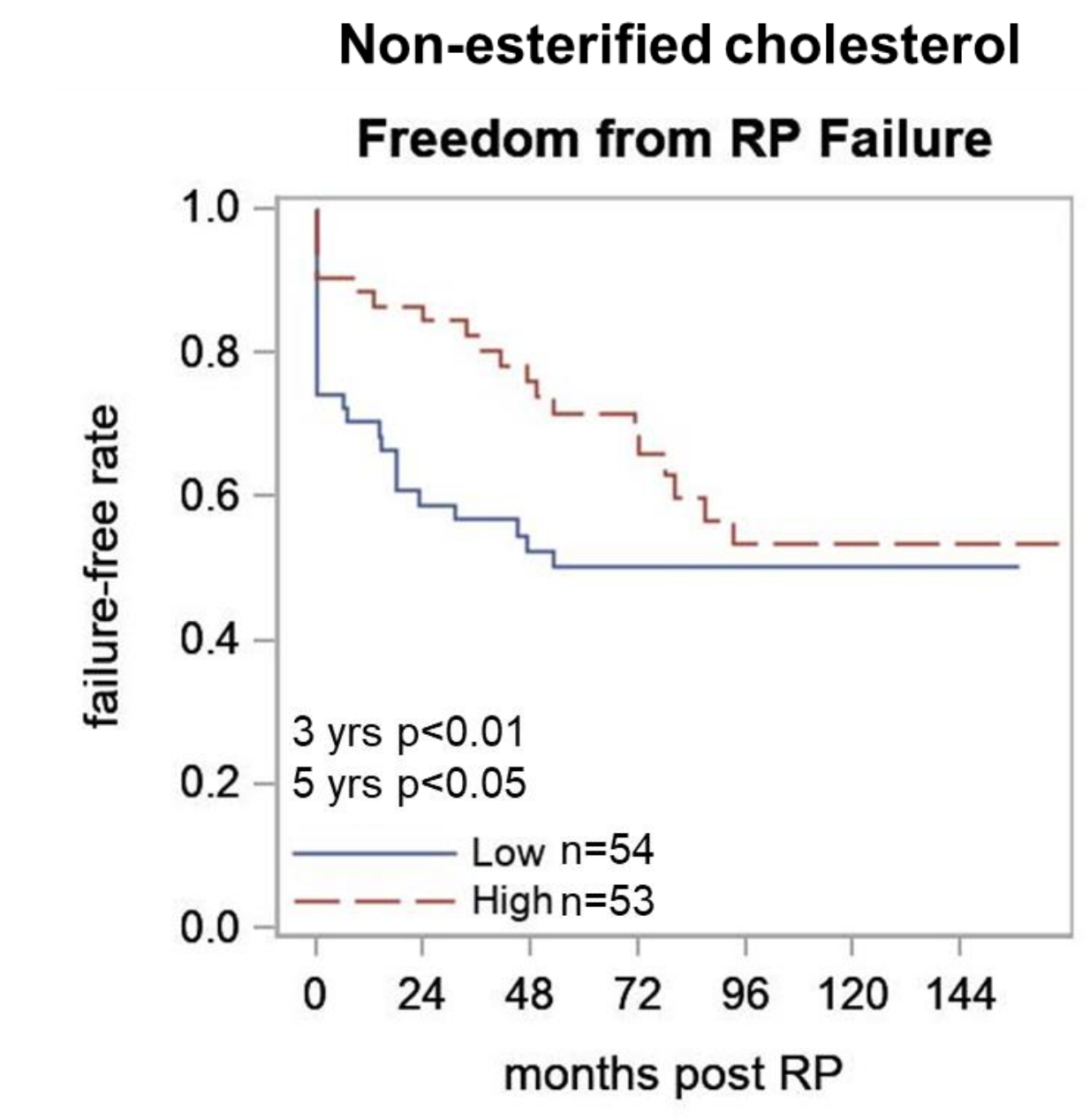

ASD

Freedom from RP Failure

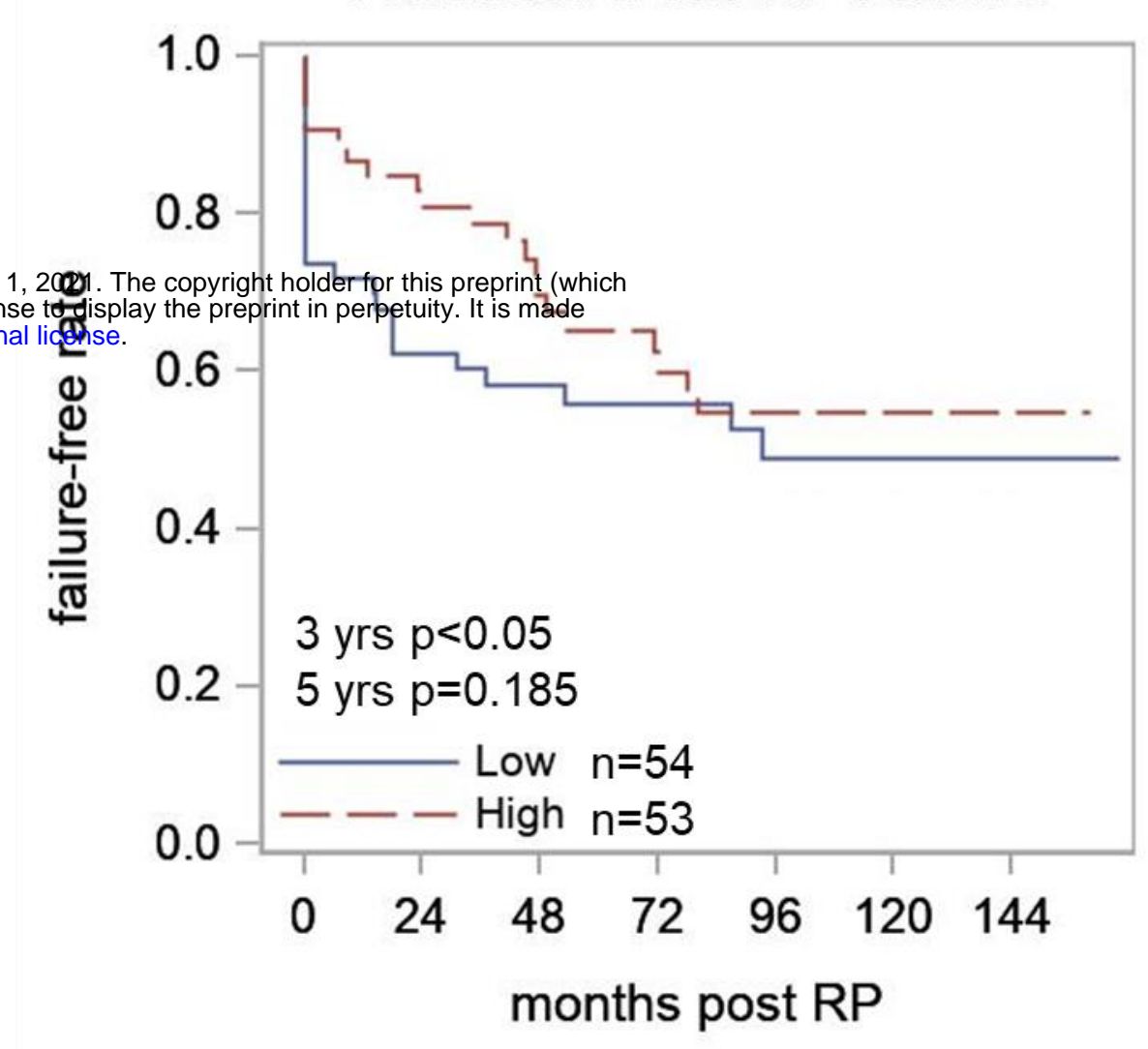

Progesterone

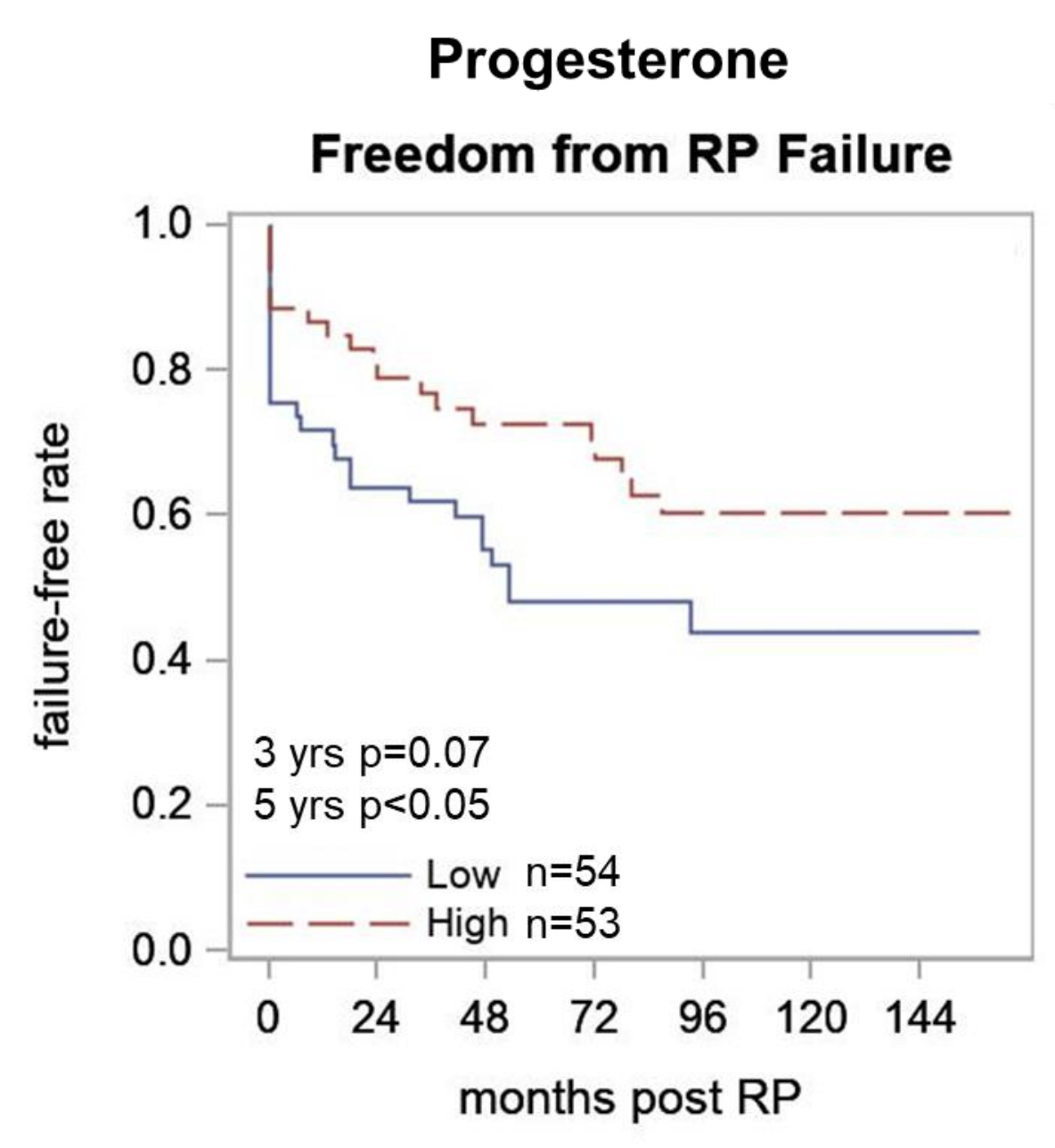

Corticosterone

Freedom from RP Failure

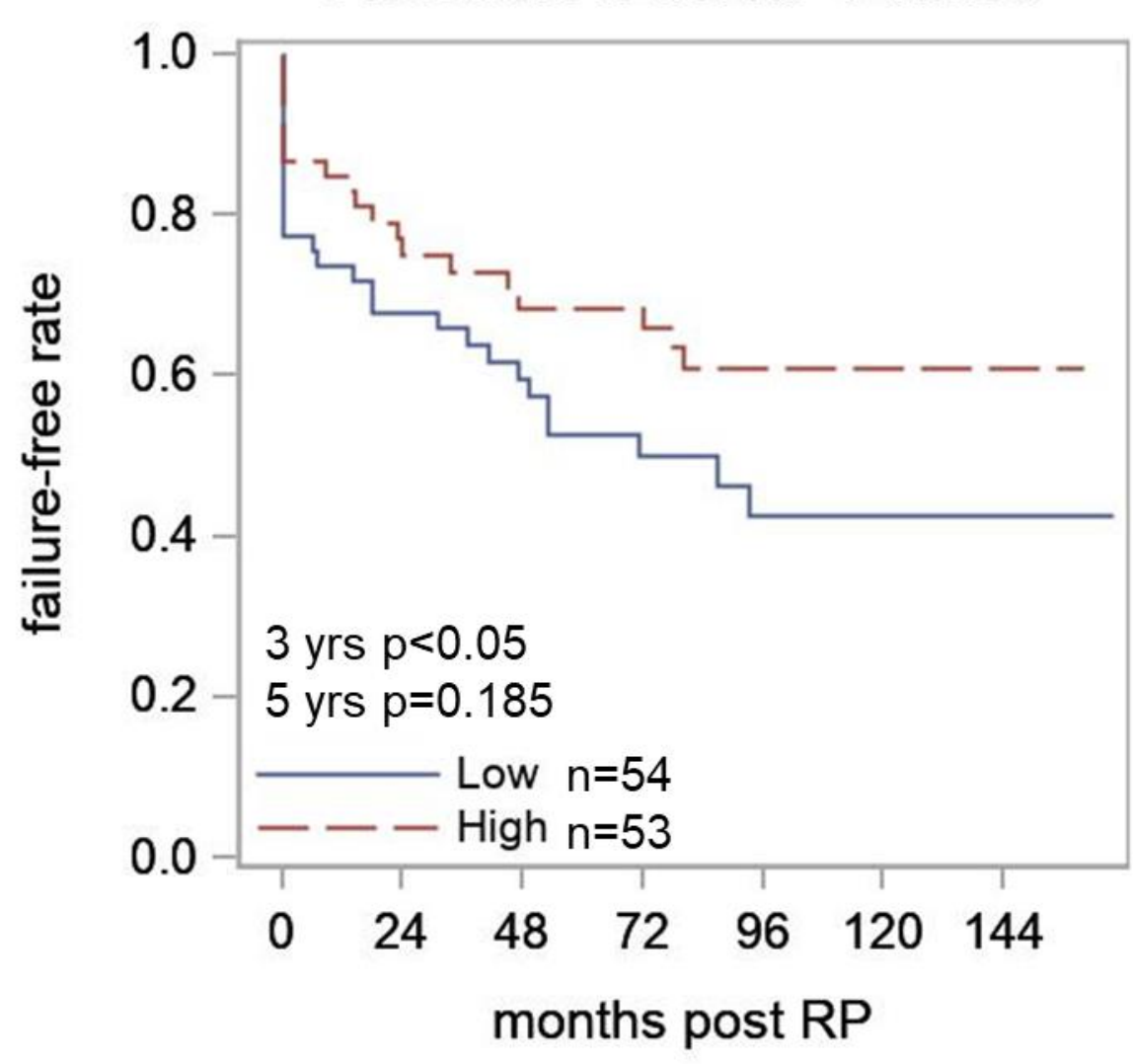

SHBG

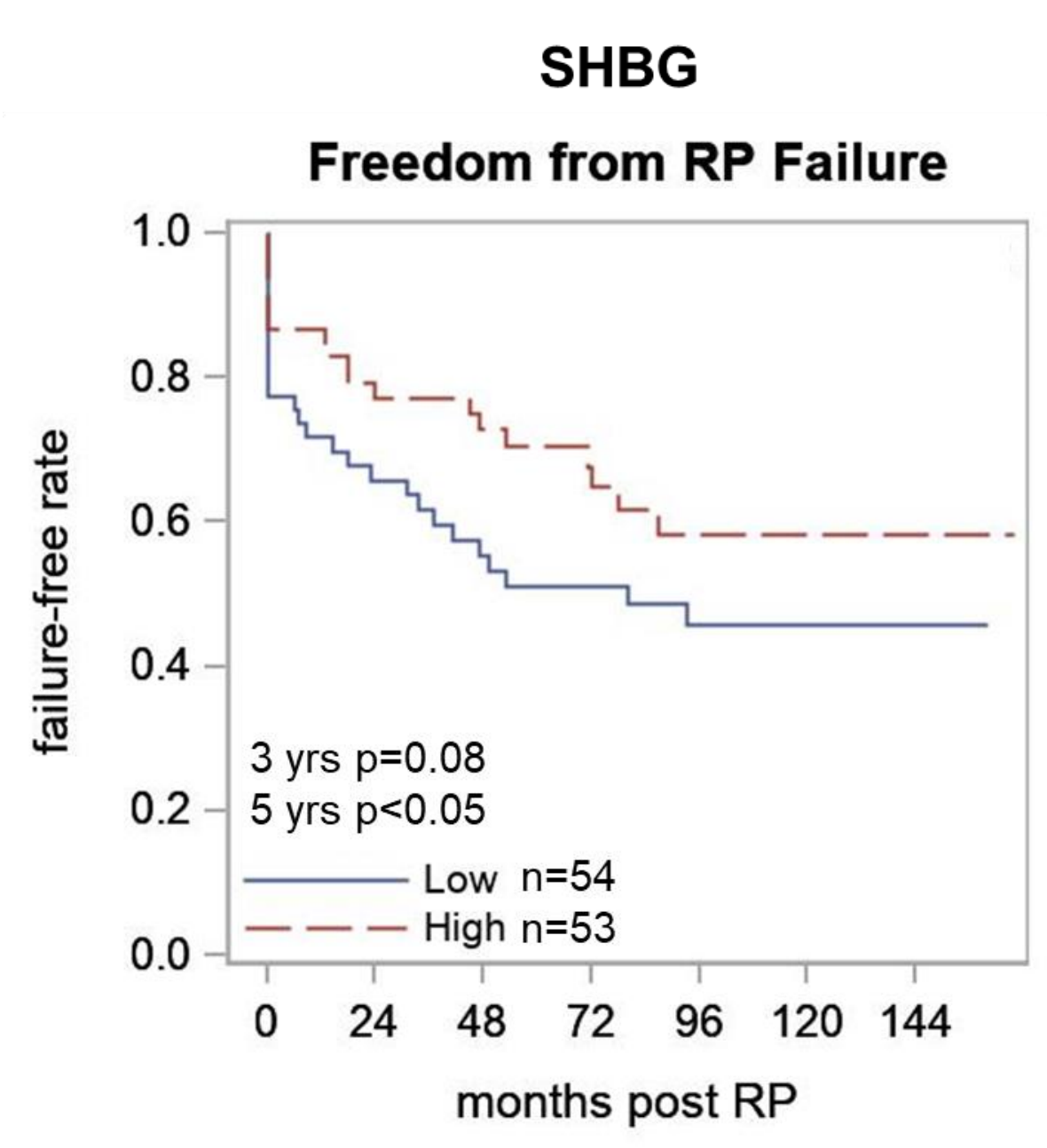

Deoxycorticosterone

Freedom from RP Failure

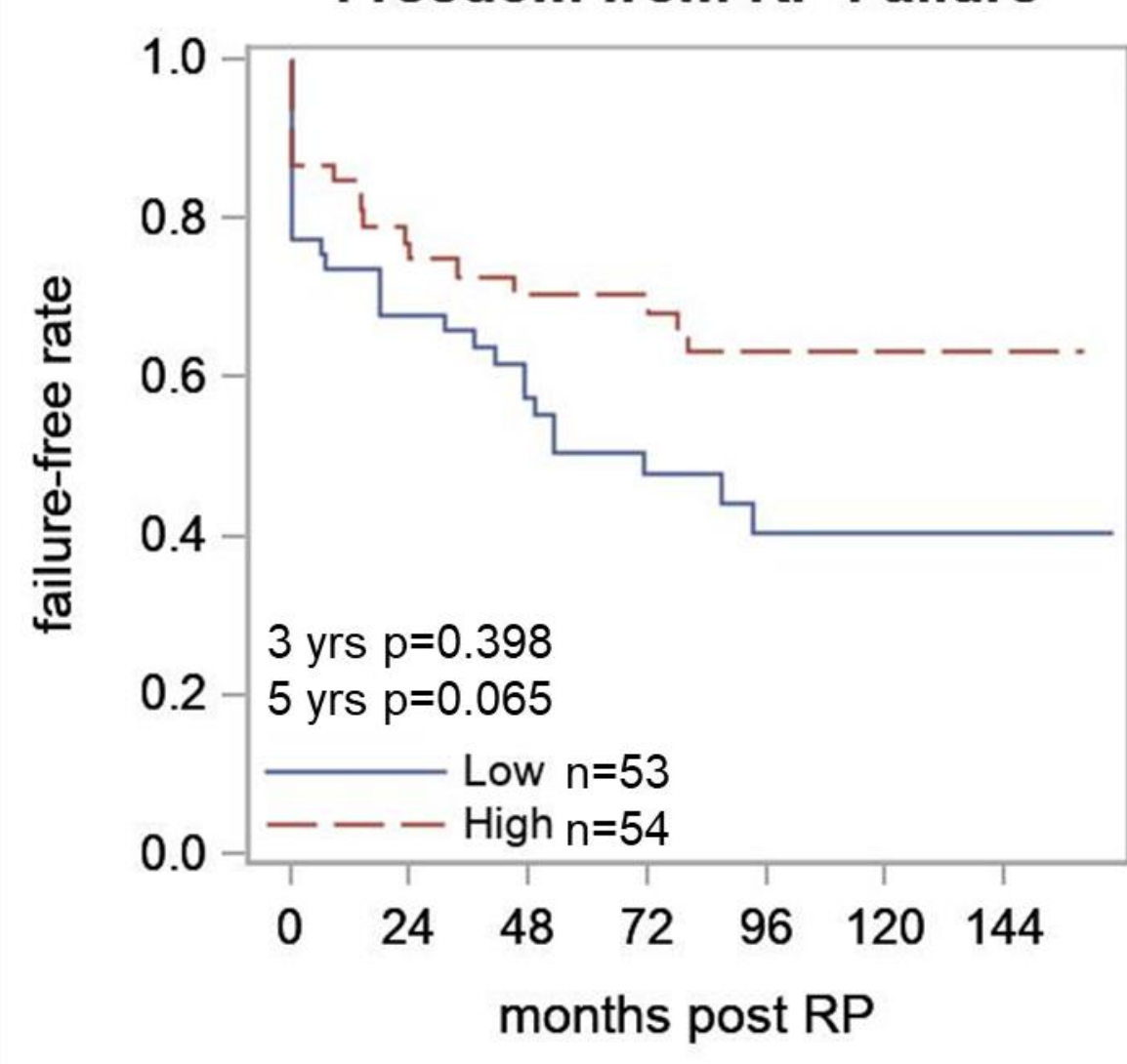




\section{Figure 8}

A. African American Samples

A. Enrichment Scores $\sim$ Metabolite Level

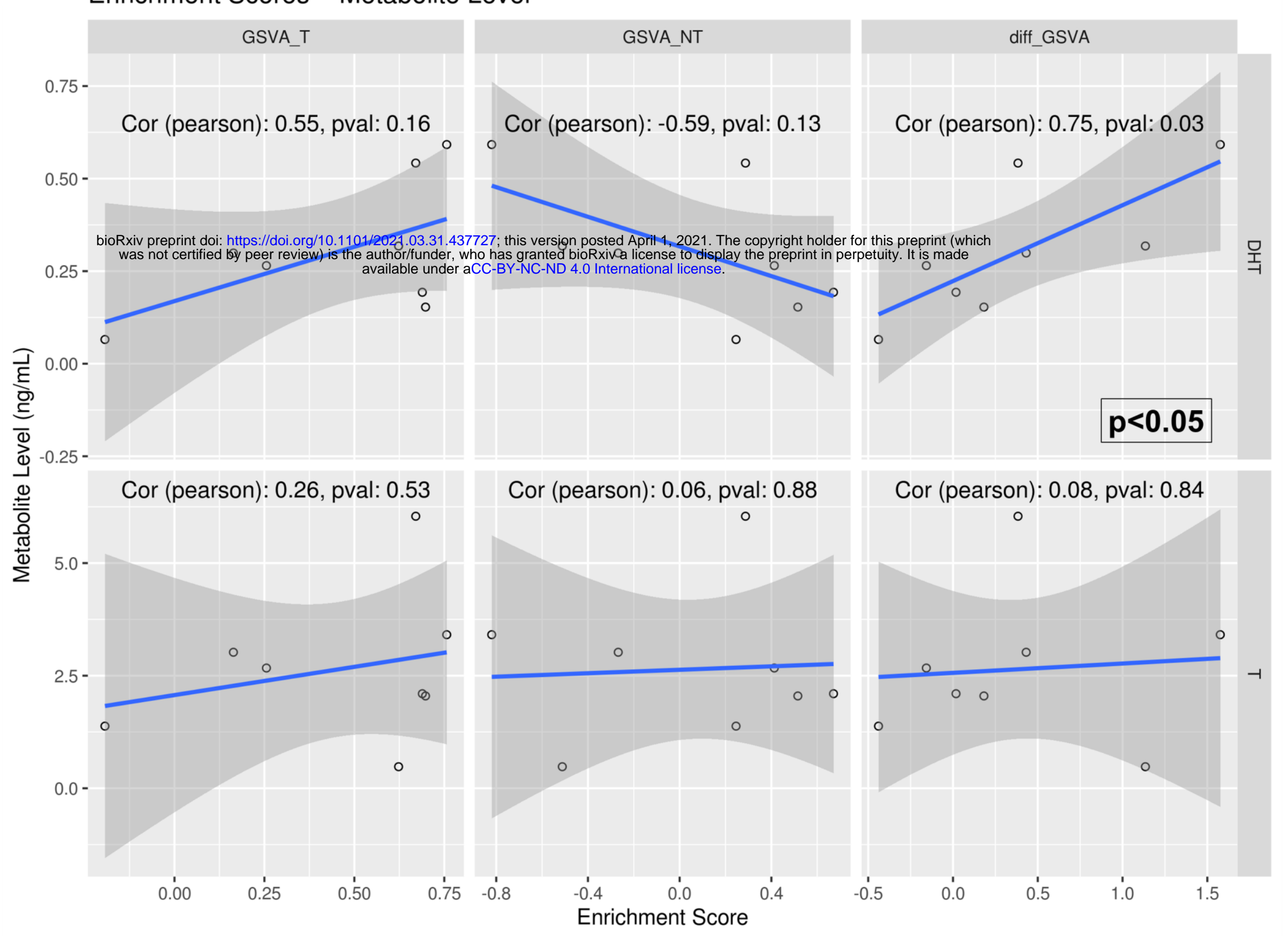

B. European American Samples

Enrichment Scores Metabolite Level

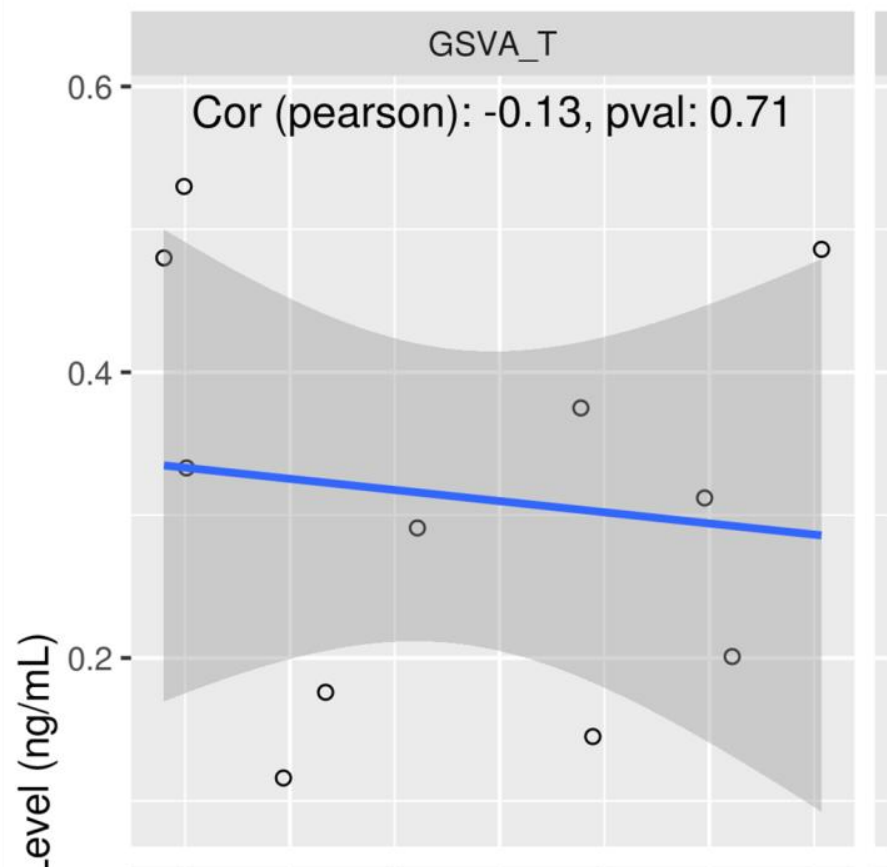

Cor (pearson): 0.07 , pval: 0.84

$\sum^{\frac{\pi}{0}}$

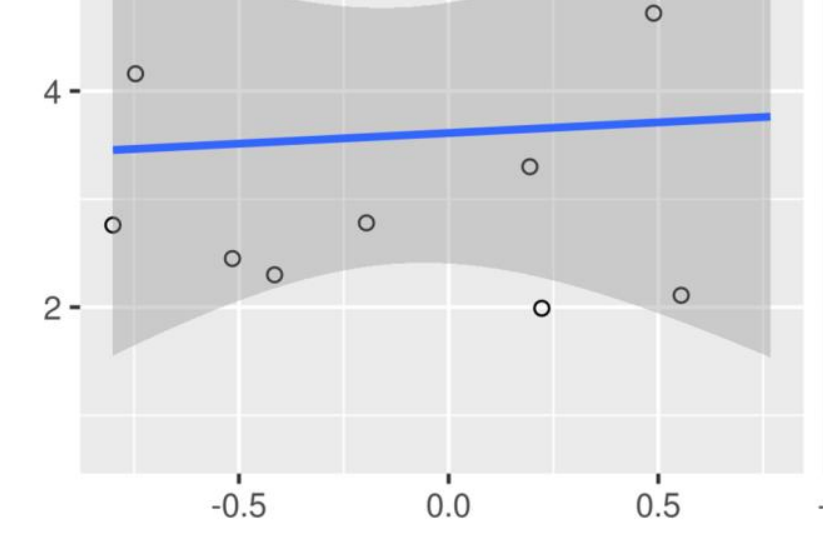

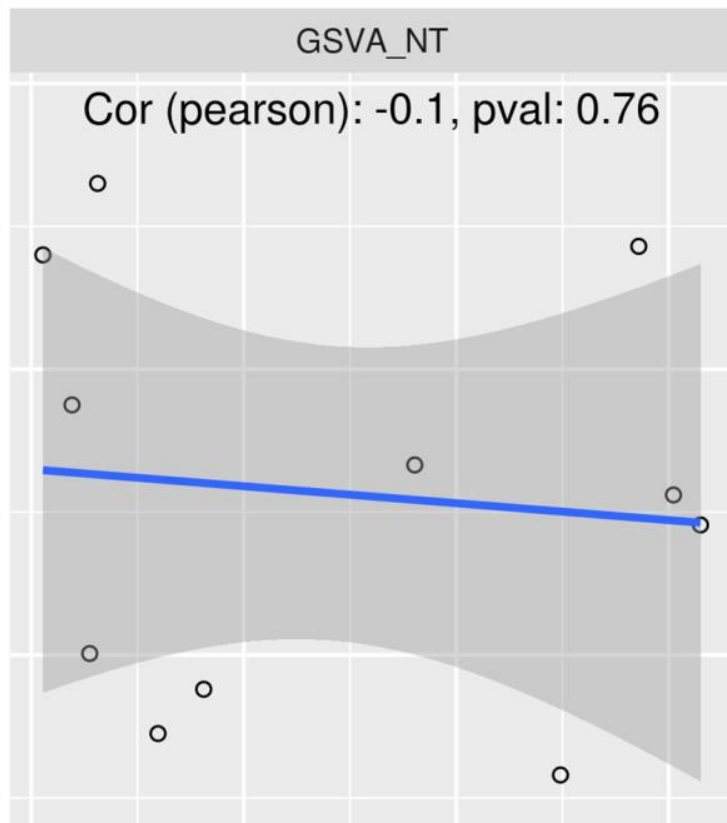

Cor (pearson): 0.25 , pval: 0.45 $\circ$

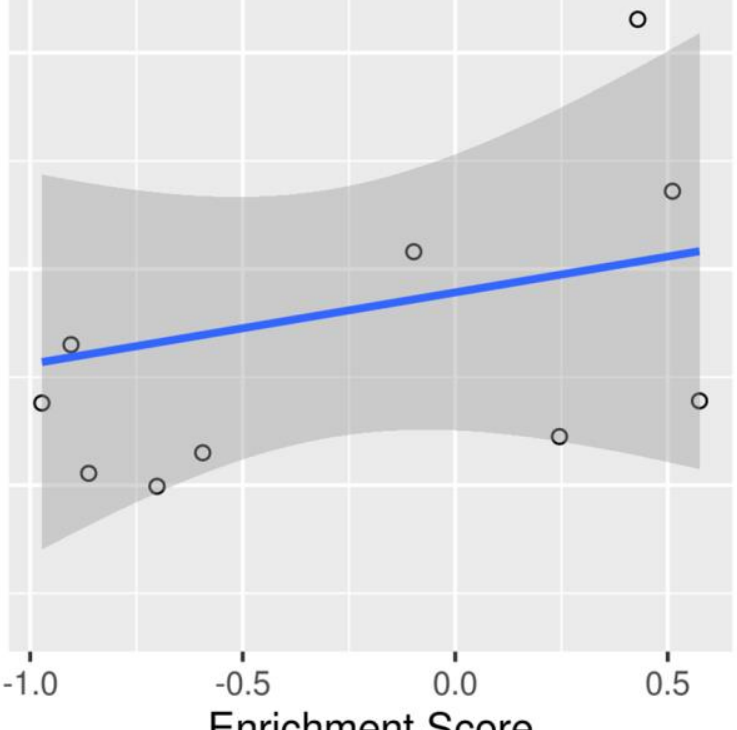
Cor (pearson): -0.01, pval: 0.98

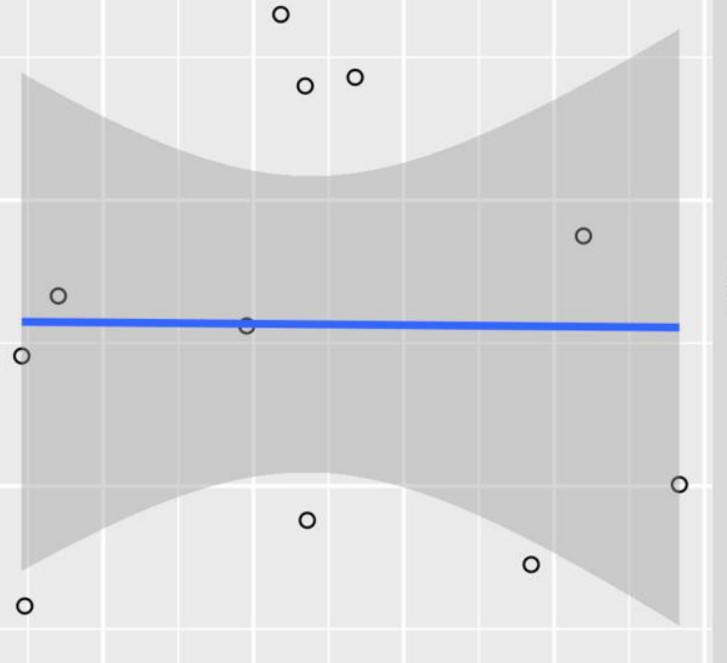

Cor (pearson): -0.16 , pval: 0.63 $\circ$ 。

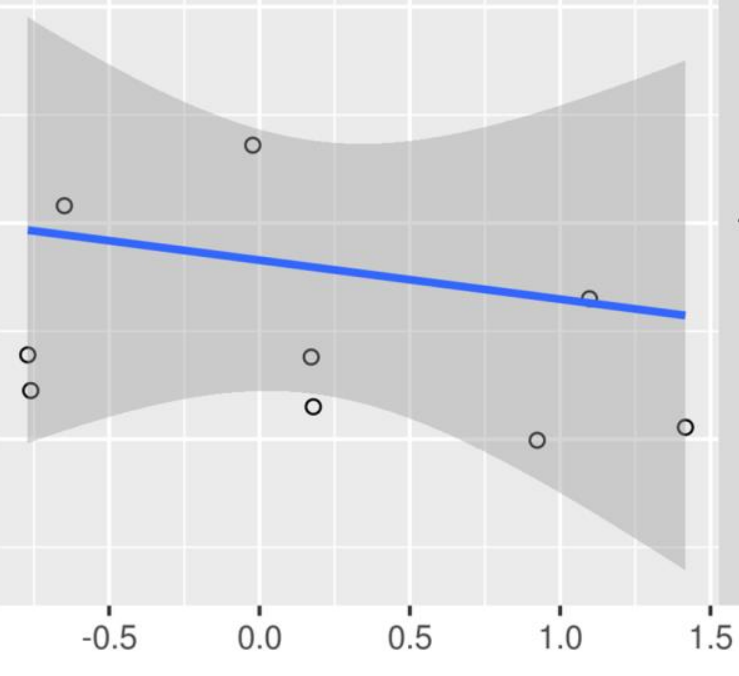


bioRxiv preprint doi: https://doi.org/10.1101/2021.03.31.437727; this version posted April 1, 2021. The copyright holder for this preprint (which was not certified by peer review) is the author/funder, who has granted bioRxiv a license to display the preprint in perpetuity. It is made available under aCC-BY-NC-ND 4.0 International license.

\begin{tabular}{|c|c|c|c|c|}
\hline Metabolite & & $\overline{\mathbf{A A}}$ & EA & p-value \\
\hline \multirow[t]{2}{*}{$17 \alpha-\mathrm{OH}$-Progesterone $(\mathrm{ng} / \mathrm{mL})$} & Mean/Std/N & $0.67 / 0.40 / 38$ & $0.81 / 0.35 / 69$ & \multirow{2}{*}{$<0.05$} \\
\hline & Median/Min/Max & $0.50 / 0.18 / 1.91$ & $0.77 / 0.10 / 1.91$ & \\
\hline \multirow[t]{2}{*}{ 20a-Dihyro-progesterone (ng/mL) } & Mean/Std/N & $0.05 / 0.04 / 38$ & $0.07 / 0.02 / 69$ & \multirow{2}{*}{$<0.01$} \\
\hline & Median/Min/Max & $\mathrm{BLQ} / \mathrm{BLQ} / 0.22$ & $0.07 / \mathrm{BLQ} / 0.13$ & \\
\hline \multirow[t]{2}{*}{ Aldosterone (ng/mL) } & Mean/Std/N & $0.22 / 0.19 / 38$ & $\mathrm{BLQ} / \mathrm{NA} / 69$ & \multirow{2}{*}{$<0.01$} \\
\hline & Median/Min/Max & $\mathrm{BLQ} / \mathrm{BLQ} / 1.07$ & $\mathrm{BLQ} / \mathrm{BLQ} /-1.00$ & \\
\hline \multirow[t]{2}{*}{ All observed Androsterone (AND) (ng/mL) } & Mean/Std/N & $0.12 / 0.09 / 38$ & $0.13 / 0.09 / 69$ & \multirow{2}{*}{0.14} \\
\hline & Median/Min/Max & $0.09 / 0.01 / 0.43$ & $0.11 / 0.02 / 0.59$ & \\
\hline \multirow[t]{2}{*}{ Androstenedione (ASD) (ng/mL) } & Mean/Std/N & $0.55 / 0.33 / 38$ & $0.63 / 0.33 / 69$ & \multirow{2}{*}{0.23} \\
\hline & Median/Min/Max & $0.47 / 0.17 / 2.03$ & $0.55 / 0.13 / 1.99$ & \\
\hline \multirow[t]{2}{*}{ Corticosterone $(\mathrm{ng} / \mathrm{mL})$} & Mean/Std/N & $1.80 / 1.77 / 38$ & $3.36 / 2.89 / 69$ & \multirow{2}{*}{$<0.01$} \\
\hline & Median/Min/Max & $1.30 / 0.30 / 8.46$ & $2.33 / 0.28 / 14.18$ & \\
\hline \multirow[t]{2}{*}{ Cortisol (ng/mL) } & Mean/Std/N & $66.03 / 24.63 / 38$ & $82.95 / 24.66 / 69$ & \multirow{2}{*}{$<0.01$} \\
\hline & Median/Min/Max & $69.42 / 19.84 / 115.40$ & $87.73 / 14.00 / 135.64$ & \\
\hline \multirow[t]{2}{*}{ Cortisone (ng/mL) } & Mean/Std/N & $14.39 / 4.80 / 38$ & $14.95 / 4.22 / 69$ & \multirow{2}{*}{0.34} \\
\hline & Median/Min/Max & $14.94 / 5.57 / 23.76$ & $15.56 / 1.64 / 22.94$ & \\
\hline \multirow[t]{2}{*}{ Dehydroepiandrosterone (DHEA) (ng/mL) } & Mean/Std/N & $1.19 / 1.00 / 38$ & $1.47 / 1.19 / 68$ & \multirow{2}{*}{0.18} \\
\hline & Median/Min/Max & $0.91 / \mathrm{BLQ} / 4.73$ & $1.26 / \mathrm{BLQ} / 7.13$ & \\
\hline \multirow[t]{2}{*}{ Dihydrotestosterone (DHT) (ng/mL) } & Mean/Std/N & $0.38 / 0.29 / 38$ & $0.36 / 0.19 / 69$ & \multirow{2}{*}{0.33} \\
\hline & Median/Min/Max & $0.26 / 0.07 / 1.35$ & $0.32 / B L Q / 0.86$ & \\
\hline \multirow[t]{2}{*}{ Deoxy-corticosterone (ng/mL) } & Mean/Std/N & $0.03 / 0.02 / 38$ & $0.04 / 0.03 / 69$ & \multirow{2}{*}{0.09} \\
\hline & Median/Min/Max & $0.02 / 0.01 / 0.09$ & $0.03 / \mathrm{BLQ} / 0.13$ & \\
\hline \multirow[t]{2}{*}{ Dihydro-progesterone (ng/mL) } & Mean/Std/N & $0.03 / 0.03 / 38$ & $0.03 / 0.03 / 69$ & \multirow{2}{*}{0.54} \\
\hline & Median/Min/Max & $0.02 / \mathrm{BLQ} / 0.20$ & $0.03 / \mathrm{BLQ} / 0.12$ & \\
\hline \multirow[t]{2}{*}{ Epi-Androsterone (ng/mL) } & Mean/Std/N & $0.18 / 0.16 / 36$ & $0.17 / 0.12 / 67$ & 067 \\
\hline & Median/Min/Max & $0.12 / 0.05 / 0.70$ & $0.12 / 0.04 / 0.50$ & 0.67 \\
\hline Epi-Testosterone (ng/mL) & Mean/Std/N & $0.05 / 0.03 / 38$ & $0.04 / 0.02 / 69$ & \\
\hline & Median/Min/Max & $0.04 / 0.02 / 0.12$ & $0.04 / \mathrm{BLQ} / 0.10$ & .61 \\
\hline Estrone (ng/mL) & Mean/Std/N & $0.04 / 0.02 / 38$ & $0.04 / 0.01 / 69$ & 17 \\
\hline & Median/Min/Max & $0.04 / \mathrm{BLQ} / 0.11$ & $0.03 / \mathrm{BLQ} / 0.08$ & 0. \\
\hline Hydroxy Pregnenolone (ng/mL) & Mean/Std/N & $0.98 / 1.09 / 38$ & $1.26 / 1.12 / 69$ & 024 \\
\hline & Median/Min/Max & $0.68 / 0.18 / 6.04$ & $0.98 / \mathrm{BLQ} / 6.41$ & 0.24 \\
\hline Non-esterified cholesterol $(\mu \mathrm{g} / \mathrm{mL})$ & Mean/Std/N & $85.94 / 17.52 / 38$ & $99.48 / 72.18 / 69$ & \\
\hline & Median/Min/Max & $80.95 / 63.20 / 126.00$ & $86.40 / 58.20 / 658.00$ & 0.5 \\
\hline Pregnenolone (ng/mL) & Mean/Std/N & $0.58 / 0.30 / 38$ & $0.68 / 0.26 / 69$ & 01 \\
\hline & Median/Min/Max & $0.51 / \mathrm{BLQ} / 1.35$ & $0.62 / 0.27 / 1.41$ & .01 \\
\hline Progesterone (ng/mL) & Mean/Std/N & $0.03 / 0.03 / 38$ & $0.04 / 0.02 / 69$ & $\cap 01$ \\
\hline & Median/Min/Max & $0.03 / \mathrm{BLQ} / 0.19$ & $0.04 / 0.01 / 0.10$ & $<0.01$ \\
\hline Sex hormone binding globulin (SHBG) (nmol/L) & Mean/Std/N & $42.83 / 25.59 / 38$ & $40.82 / 17.59 / 69$ & \\
\hline & Median/Min/Max & $31.10 / 16.30 / 122.00$ & $40.10 / 17.70 / 114.00$ & 0.41 \\
\hline Testosterone (T) (ng/mL) & Mean/Std/N & $3.64 / 2.02 / 38$ & $3.99 / 1.62 / 69$ & 0,05 \\
\hline & Median/Min/Max & $3.25 / 0.48 / 9.61$ & $3.47 / 0.07 / 8.90$ & .05 \\
\hline
\end{tabular}


Table 2 AR protein expression and clinicopathological parameters of PrCa from AA and EA men

\begin{tabular}{|c|c|c|c|c|c|}
\hline \multicolumn{2}{|c|}{ AR (\% of positive nuclei) } & $\mathrm{n}$ (Tumors) & Mean (SD) & Median (IQR) & p-value \\
\hline \multirow{2}{*}{ Age } & $<55$ & 80 & $78.17(14.07)$ & $80.93(71.20-88.03)$ & \multirow[b]{2}{*}{0.14} \\
\hline & $>=55$ & 173 & $74.95(16.83)$ & $78.43(66.15-87.43)$ & \\
\hline \multirow{2}{*}{ Race } & $\overline{E A}$ & 133 & $75.50(17.25)$ & $79.37(65.63-89.40)$ & \multirow{2}{*}{0.60} \\
\hline & $\mathrm{AA}$ & 107 & $76.57(13.24)$ & $78.87(71.13-86.17)$ & \\
\hline \multirow{4}{*}{ PSA } & $<4$ & 40 & $74.15(13.27)$ & $73.53(66.91-85.75)$ & \multirow{4}{*}{0.71} \\
\hline & 4 to $<10$ & 152 & $76.44(16.11)$ & $80.13(69.10-88.55)$ & \\
\hline & 10 to $<20$ & 28 & $75.47(17.18)$ & $80.02(65.53-83.08)$ & \\
\hline & $>=20$ & 19 & $78.95(13.76)$ & $80.93(76.33-88.77)$ & \\
\hline \multirow{2}{*}{ Clinical Gleason } & $<=3+4$ & 138 & $75.25(15.29)$ & $78.28(67.67-85.25)$ & \multirow[b]{2}{*}{0.35} \\
\hline & $>=4+3$ & 101 & $77.17(16.14)$ & $80.47(68.50-90.00)$ & \\
\hline \multirow{2}{*}{ Persistent Disease? } & No & 200 & $75.80(15.82)$ & $78.37(66.73-87.58)$ & \multirow{2}{*}{0.75} \\
\hline & Yes & 53 & $76.60(17.06)$ & $80.27(71.13-86.80)$ & \\
\hline \multirow{2}{*}{ Hormone Tx } & No & 197 & $76.09(15.80)$ & $79.00(66.20-87.43)$ & \multirow{2}{*}{0.82} \\
\hline & & 56 & $75.54(17.06)$ & $80.20(69.62-87.77)$ & \\
\hline
\end{tabular}

\begin{tabular}{|c|c|c|c|c|c|c|c|c|}
\hline \multirow{2}{*}{\multicolumn{2}{|c|}{$\begin{array}{c}\text { AR (\% of positive nuclei) } \\
\text { Tumor }\end{array}$}} & \multicolumn{3}{|c|}{$\overline{\mathbf{A A}}$} & \multicolumn{3}{|c|}{ EA } & \multirow{4}{*}{$\frac{\text { Interaction P-value }}{0.28}$} \\
\hline & & $\mathbf{n}$ & Mean (SD) & P-value & $\mathrm{n}$ & Mean (SD) & P-value & \\
\hline \multirow{2}{*}{ Age } & $<55$ & 46 & $77.59(11.80)$ & \multirow{2}{*}{0.49} & 29 & $80.63(13.93)$ & \multirow{2}{*}{0.07} & \\
\hline & $>=55$ & 61 & $75.80(14.28)$ & & 104 & $74.07(17.86)$ & & \\
\hline \multirow{4}{*}{$\mathrm{PSA}^{*}$} & $<4$ & 16 & $72.18(13.65)$ & \multirow{4}{*}{0.15} & 24 & $75.47(13.15)$ & \multirow{4}{*}{0.96} & \multirow{4}{*}{0.38} \\
\hline & 4 to $<10$ & 70 & $77.91(12.02)$ & & 82 & $75.18(18.91)$ & & \\
\hline & 10 to $<20$ & 12 & $72.53(19.51)$ & & 16 & $77.68(15.49)$ & & \\
\hline & $>=20$ & 8 & $82.51(5.55)$ & & 10 & $74.49(17.08)$ & & \\
\hline \multirow{2}{*}{ Clinical Gleason } & $<=3+4$ & 61 & $77.61(12.30)$ & \multirow{2}{*}{0.35} & 76 & $73.10(17.07)$ & \multirow{2}{*}{0.06} & \multirow{2}{*}{$<0.05$} \\
\hline & $>=4+3$ & 46 & $75.19(14.43)$ & & 55 & $78.82(17.40)$ & & \\
\hline \multirow{2}{*}{ Persistent Disease? } & No & 84 & $76.34(12.96)$ & \multirow{2}{*}{0.74} & 106 & $75.20(17.17)$ & \multirow{2}{*}{0.69} & \multirow{2}{*}{0.93} \\
\hline & Yes & 23 & 77.39 (14.49) & & 27 & $76.70(17.81)$ & & \\
\hline \multirow{2}{*}{ Hormone Tx } & No & 86 & $76.62(13.26)$ & \multirow{2}{*}{0.93} & 100 & $75.32(17.07)$ & \multirow{2}{*}{0.83} & \multirow{2}{*}{0.84} \\
\hline & Yes & 21 & $76.35(13.49)$ & & 33 & $76.06(18.02)$ & & \\
\hline \multicolumn{2}{|c|}{ AR (\% of positive nuclei) } & \multicolumn{3}{|c|}{$\overline{\mathbf{A A}}$} & \multicolumn{3}{|c|}{ EA } & \\
\hline \multicolumn{2}{|c|}{ Adjacent non-tumor } & $\mathbf{n}$ & Mean (SD) & P-value & $\mathbf{n}$ & Mean (SD) & P-value & Interaction P-value \\
\hline \multirow{2}{*}{ Age } & $<55$ & 46 & $80.19(9.90)$ & \multirow{2}{*}{0.16} & 29 & $78.09(16.58)$ & \multirow{2}{*}{$<0.05$} & \multirow{2}{*}{0.22} \\
\hline & $>=55$ & 61 & $76.63(14.82)$ & & 104 & $68.68(19.28)$ & & \\
\hline & $<4$ & 16 & $74.41(14.14)$ & & 24 & $69.00(12.61)$ & & \\
\hline PSA & 4 to $<10$ & 70 & $80.57(10.70)$ & $<005$ & 82 & $71.06(20.26)$ & 0.97 & 0.5 \\
\hline$P S A$ & 10 to $<20$ & 12 & $70.36(21.56)$ & & 16 & $70.71(20.98)$ & & \\
\hline & $>=20$ & 8 & $75.48(7.94)$ & & 10 & $71.38(21.87)$ & & \\
\hline & $<=3+4$ & 61 & $76.66(12.55)$ & & 76 & $69.95(19.27)$ & & \\
\hline Clinical Gleason & $>=4+3$ & 46 & $80.15(13.45)$ & 0.17 & 55 & $71.31(19.07)$ & 0.69 & 0.63 \\
\hline & No & 84 & $79.27(11.86)$ & & 106 & $70.05(18.91)$ & & \\
\hline Persistent Disease? & Yes & 23 & $74.09(16.18)$ & 0.09 & 27 & $73.39(19.80)$ & 0.42 & 0.11 \\
\hline Hormone $\mathrm{Tx}$ & No & 86 & $80.45(10.74)$ & $<0.001<>>$ & 100 & 70.59 (17.92) & 0.88 & $<0.05$ \\
\hline & Yes & 21 & $68.78(17.03)$ & & 33 & $71.15(22.47)$ & & \\
\hline
\end{tabular}

\begin{tabular}{|c|c|c|c|c|c|}
\hline \multicolumn{2}{|c|}{ AR (\% of positive nuclei) } & $\mathrm{n}$ (Adjacent non tumors) & Mean (SD) & Median (IQR) & \multirow{3}{*}{$\begin{array}{l}\text { p-value } \\
<0.001\end{array}$} \\
\hline \multirow[b]{2}{*}{ Age } & $<55$ & 80 & $79.68(13.00)$ & $82.18(72.93-88.45)$ & \\
\hline & $>=55$ & 173 & $71.72(18.73)$ & $74.53(64.30-82.47)$ & \\
\hline \multirow{2}{*}{ Race } & $E A$ & 133 & $70.73(19.06)$ & $73.40(63.67-82.33)$ & \multirow{2}{*}{$<0.001$} \\
\hline & AA & 107 & $78.16(13.00)$ & $79.77(70.03-87.93)$ & \\
\hline \multirow{4}{*}{ PSA } & $<4$ & 40 & $71.16(13.34)$ & $72.15(62.80-79.60)$ & \multirow{4}{*}{0.35} \\
\hline & 4 to $<10$ & 152 & $75.44(17.18)$ & $77.97(68.83-86.28)$ & \\
\hline & 10 to $<20$ & 28 & $70.56(20.83)$ & $70.40(58.90-88.88)$ & \\
\hline & $>=20$ & 19 & $74.25(16.99)$ & $77.07(59.03-89.23)$ & \\
\hline \multirow{2}{*}{ Clinical Gleason } & $<=3+4$ & 138 & $73.08(16.92)$ & $76.96(67.50-84.43)$ & \multirow[b]{2}{*}{0.31} \\
\hline & $>=4+3$ & 101 & $75.34(17.24)$ & $76.80(65.63-88.13)$ & \\
\hline \multirow{2}{*}{ Persistent Disease? } & No & 200 & $74.19(17.31)$ & $76.65(67.43-86.52)$ & \multirow{2}{*}{0.94} \\
\hline & Yes & 53 & $74.41(18.38)$ & $79.10(65.50-85.80)$ & \\
\hline \multirow{2}{*}{ Hormone $\mathrm{Tx}$} & No & 197 & $75.29(16.46)$ & $77.80(68.43-86.53)$ & \multirow{2}{*}{0.07} \\
\hline & Yes & 56 & $70.54(20.48)$ & $72.20(59.32-84.83)$ & \\
\hline
\end{tabular}

